\title{
EL CRECIMIENTO ECONOMICO \\ NOVOHISPANO DURANTE EL SIGLO XVIII: \\ UNA REVISION
}

\author{
PEDRO PEREZ HERRERO \\ Universidad Complutense
}

Tradicionalmente la segunda mitad del siglo xvill de la historia de la Nueva España ha sido interpretada como una época de «luces», crecimiento, apertura, modernidad. Su brillo era constantemente comparado con el período opaco de «crisis» del siglo xvir, considerado como oscurantista y atrasado, o el de la «anarquía» de la primera mitad del siglo xIX. El primero era tiempo de fracaso en el que no se había logrado imponer la autoridad de la Corona sobre las pretensiones autonomistas criollas, en el que el visitador Gelves había sido destituido y echado de la Nueva España y en el que la Corona había sido agredida por el constante contrabando, la injerencia de otras potencias en el negocio indiano y la continua corrupción. El segundo era tiempo de revuelta, cuartelazos, desorden, guerra, déficit fiscal. Entre ambas épocas relucía el siglo xvirI con la luz propia que le daba su orden, riqueza y sentido de triunfo en el que Gálvez, como visitador, se había impuesto sobre los criollos. Desde hace ya algunos años, esta visión contrastada en blanco y negro, crisis y crecimiento, sombras y luces, está siendo desmontada ${ }^{1}$.

En primer lugar, existen algunos trabajos que, criticando las tesis respectivas de "crisis» o "anarquía» de los siglos XVII y xIX, reducen el brillo de la centuria del despotismo ilustrado. W. Borah, hace bastante tiempo, lanzó la tesis de la depresión del virreinato novohispano entre la gran epidemia de matlazáhuatl de 1576 y los años finales del siglo xvir. Según dicho autor, la causa principal fue la escasez de mano de obra, y señala el año de 1650 como el del nadir de la población indígena (1.200.000 habitantes para todo el virreinato). Sin brazos suficientes, las minas se encontraron sin trabajadores, las haciendas sin peones, el consumo decayó y, por tanto, la producción y la inversión disminuyeron. Esta reducción en la disponibilidad

' Una versión preliminar de este texto fue presentada al XIII Simposio de Análisis Económico (Barcelona, 28-30 de septiembre de 1988). Deseo agradecer los comentarios de sus participantes, y en especial de Josep Fontana. Con respecto a España, y más concretamente a Madrid, véase Equipo Madrid (1988). 
de alimentos amenazó el bienestar de las ciudades coloniales en constante crecimiento, en las que una numerosa población dependía para su sustento de la fuerza de trabajo indígena. La introducción de mejoras técnicas pudo haber ampliado la producción, pero no se tiene constancia de que las innovaciones se aplicaran, al menos masivamente. El peonaje por deudas, que encadenaba al trabajador a las respectivas unidades de produçción, fue el resultado para asegurarse la siempre escasa mano de obra ${ }^{2}$.

F. Chevalier argumentó que durante el siglo xvir se formaron unidades productivas próximas a la autosuficiencia - las haciendas - con formas de vida señoriales muy cercanas o similares a las de la época feudal europea ${ }^{3}$. P. y H. Chaunu reforzaron la tesis de la «crisis» planteando que la depresión de la mencionada centuria no era local, sino internacional - del mundo occidental-, ya que se podía comprobar, a través de los registros de la Casa de Contratación y la Caja Real de Acapulco, cómo los volúmenes de los intercambios habían descendido notablemente en los años centrales del siglo xvir. Argumentaron que si el tráfico disminuyó no fue más que por una reducción de la producción interna, debida evidentemente al descenso demográfico postulado por Borah. Corrigieron, sin embargo, la fecha inicial de la «crisis», retrasándola a $1620^{4}$.

Posteriores estudios han comenzado a plantear una revisión de estas posturas. A nivel demográfico se han hecho algunas rectificaciones. J. Miranda propuso que el comienzo de la recuperación debió de ser alrededor de 1630, momento en el que la población alcanzó los 1,5 millones de habitantes $^{5}$. Ch. Gibson subrayó que cada región tenía un ritmo diferente, por lo que si durante el siglo Xvir hubo un descenso demográfico, éste se comportó de forma desigual en cada zona ${ }^{6}$. A. Lira y L. Muro subrayaron, con precisión, que hay que conectar la disminución de la población indígena con el aumento de los mestizos, ya que la primera, para eludir el tributo, se hacía pasar como no indígena ?. Más recientemente, C. Rabell ha comprobado que durante la segunda mitad del siglo xvir, al menos en la parte del Bajío, se dio una fuerte recuperación demográfica, alcanzándose altas tasas de crecimiento ${ }^{8}$.

J. Lynch señaló, por su parte, que la tesis de P. y $\mathrm{H}$. Chaunu quizá no fuera muy válida, ya que se podía interpretar que lo que estaba pasando era que la Nueva España, en vez de exportar sus riquezas por los canales oficiales

2 Borah (1951).

3 Chevalier (1953).

4 Chaunu (1955-60).

3 Miranda (1962).

- Gibson (1967).

7 Lira y Muro (1977).

- Rabell Romero (1984). 
hacia la península, lo hiciera ilegalmente hacia otros mercados o simplemente las consumiera o reinvirtiera en su propio suelo. Nueva España se convirtió en más autosuficiente, disminuyendo su dependencia con respecto al exterior. Si no importaba textiles era no porque no los consumiera, sino porque los producía dentro de sus fronteras o los adquiría de contrabando tanto de Europa como de Asia. La relación metrópoli/colonias varió. No es, por tanto, depresión, sino autonomía ${ }^{9}$.

J. P. Bakewell observó para el caso específico de Zacatecas que el real minero en ningún momento sufrió de escasez de mano de obra, sino que, por el contrario, su producción siguió al alza hasta 1635, en que comenzó a decaer por otras causas, como la falta de mercurio y de capitales y el empobrecimiento de las vetas. Con respecto al argumento de P. y $\mathrm{H}$. Chaunu, subrayó que éstos hicieron un diagnóstico de la situación interna del virreinato utilizando elementos "externos" — comercio exterior-, cuando es posible detectar una desconexión entre ambos, como señalara ya Lynch. Zacatecas estaba en todo su apogeo en los años (1610-1630) de la «depresión» de W. Borah y de la «crisis» de P. y H. Chaunu. Se podría hablar entonces de un proceso de sustitución de importaciones. El resultado fue que la Nueva España logró una mayor «independencia económica» con respecto a la Madre Patria. Hasta 1630, concluye, no se puede hablar de «crisis». Posteriormente la situación es menos clara ${ }^{10}$.

Por su parte, J. I. Israel se pregunta si hubo una profunda depresión a partir de los años 1630, ¿cómo se puede explicar la continuación de un cierto nivel de ingresos fiscales, procedente de impuestos a la producción y al comercio? Su respuesta es clara. El crecimiento de las recaudaciones puede ser explicado por el severo plan de ajuste fiscal programado por el conde-duque de Olivares a partir de 1621 para recaudar fondos para las empresas bélicas europeas. Por otra parte, si Zacatecas redujo su producción a partir de 1635 , otros centros mineros hicieron el relevo comenzando a lanzar volúmenes de plata crecientes al mercado, como fue el caso de Parral. No se puede, por lo tanto, en función de un solo caso, generalizar para todo el virreinato ${ }^{11}$.

J. H. TePaske y H. S. Klein han criticado la tesis de Israel. Asentándose en fuentes fiscales han concluido que no se puede mantener la tesis de la mejor eficiencia fiscal para explicar la permanencia de los niveles de ingresos cle la Real Hacienda. Concluyen que si bien no se puede hablar de "crisis». sí al menos de «paralización»"

\footnotetext{
' Lynch (1970).

10 Bakewell (1976).

"Israel (1979).

12 TePaske y Klein (1981).
} 
Al mismo tiempo, J. C. Chiaramonte ha comentado que todo parece indicar que los cuarenta años anteriores a 1620 fueron años de expansión, por lo que la «crisis» de W. Borah más parece una crisis de adaptación de los antiguos sistemas de reclutamiento de mano de obra -encomienda y repartimiento (el personaje por deudas al parecer no fue un fenómeno generalizado)-, y se pregunta ¿cómo se puede conciliar la «crisis» secular con la recuperación demográfica indudable de la segunda mitad del siglo? La respuesta que da es también clara. Se están superponiendo dos historias conexas, pero distintas. Un 80 por 100 de la población novohispana durante el siglo xvir estaba constituida por campesinos indígenas dispersos en poblados y caseríos, que no producían regularmente excedentes comerciales y, por lo tanto, no eran consumidores significativos de los productos urbanos, ni fueron afectados por las fluctuaciones del gran comercio novohispano y transatlántico. Si tenemos en cuenta, entonces, estos dos desarrollos económicos y sociales, desde luego conectados por lazos variados, el problema adquiere otro cariz. Por un lado, hay una historia del declive demográfico indígena, herencia de la conquista, y por otro, la construcción de una economía de mercado con mano de obra libre asalariada alrededor de haciendas, reales de minas, centros urbanos, etc. Son dos procesos que no deben confundirse ${ }^{13}$.

Respecto al siglo XIX, también se ha comenzado a revisar el concepto de «decadencia» que hasta ahora se tenía, al comprobarse que un aumento en el contrabando, un retroceso en la eficiencia de la maquinaria administrativa, una menor concentración de la producción, un regreso a la circulación de platas en pasta sin quintar y un menor índice de comercialización hicieron bajar las rentas. Las arcas del Estado se vaciaron y entraron en escena los agiotistas y los prestamistas internacionales. Que hubo un descenso en la producción no se discute, pero muy posiblemente no en la medida que lo indican las cifras oficiales ${ }^{14}$.

En segundo lugar, existen algunas contribuciones que han comenzado, con las cifras existentes, a hacer una crítica a la interpretación del crecimiento y desarrollo de la segunda mitad del siglo xvirr novohispano. J. H. Coatsworth ha criticado en un importante artículo la interpretación del «crecimiento" minero novohispano borbónico de los últimos años virreinales ${ }^{15}$. Sus conclusiones son, en apretada síntesis, que, deflactando las series de

${ }^{13}$ Chiaramonte (1981).

14 Pérez Herrero (1987); Salvucci (1986); Cárdenas (1984).

${ }_{15}$ Coatsworth (1986). Humboldt (1978) es uno de los responsables de esta versión de crecimiento. Le apoyó en su labor la obra de Alamán (1849-1852). Brading (1975) y Leiby (1986) son unos buenos representantes de la tesis del crecimiento económico en la actualidad. La versión del «crecimiento» también se observa, aunque con algunas matizaciones, en Klein (1985). 
"producción» minera ${ }^{16}$, el inicio del crecimiento minero no ocurrió a finales del silgo xvirI, como ya indicara R. L. Garner ${ }^{17}$, sino a comienzos de la misma centuria y más concretamente sobre la década de los años veinte, descubriendo que la industria minera se enfrentó a serios problemas a fines de la época colonial al bajar su rentabilidad, explicándose su supervivencia gracias exclusivamente al apoyo de la Corona -concedió exenciones de impuestos a la minería y mantuvo un control de precios para que éstos permanecieran bajos (pólvora, cereales, azogue, etc.), lo que en términos relativos, dado el proceso de inflación, significó una bajada real- y el desvío de recursos de otros sectores. Por consiguiente, el plan reformista borbónico no fue el que inició la recuperación minera, sino que, por el contrario, ésta se realizó antes. Lo que los «ilustrados» hicieron fue lograr que ésta se canalizara por los conductos oficiales establecidos, evitando el fraude fiscal y la circulación interna y la extracción de metales en pasta sin quintar. En consecuencia, los insurgentes no fueron los causantes de la destrucción de la minería, sino que solamente aceleraron un proceso que ya tenía los días contados. La minería se vino abajo cuando se desintegró el gobierno y cesó el apoyo que de éste recibía. Hubo crecimiento y al mismo tiempo mejoría en la administración y disminución del fraude, por lo que las cifras no reflejan toda la realidad.

Eric Van Young ha subrayado, por su parte, que el siglo xvil fue una centuria de luces y sombras, claroscuro: mientras por una parte se construían los más ricos monumentos arquitectónicos churriguerescos - Tlaxcala, Tepotzotlán, Guanajuato, etc.-, un número cada vez más elevado de mendigos deambulaba por las calles de las ciudades del virreinato y más bandidos recorrían sus caminos; mientras el comercio colonial se expandía, la maquinaria fiscal imperial extraía cantidades crecientes de metálico, ocasionando una sangría constante de circulante; mientras las élites urbanas se educaban en las modas europeas y conocían los avances científicos allende los mares, los sectores rurales seguían anclados en sus formas tradicionales de vida; mientras, en fin, una minoría de privilegiados gastaba fortunas, la gran mayoría veía rebajado su nivel de vida por el descenso de los salarios reales ocasionado por el fuerte proceso inflacionario y el estancamiento de los salarios nominales ${ }^{18}$.

Por otra parte, se ha comenzado también a poner en entredicho el perfecto funcionamiento de la tesis de la minería como «motor de arrastre», según la cual el sector minero, además de conectar las economías coloniales

${ }^{16}$ Coatsworth (1986) utiliza las cifras de «amonedación» de Orozco y Berra como de «producción".

${ }_{17}$ Garner (1980).

16 Van Young (1988); Van Young (1987). 
con el mercado mundial, fue el elemento central en la articulación de los espacios internos ${ }^{19}$. Hasta ahora se había venido interpretando que en épocas de auge minero se dio una fuerte integración de las diferentes regiones entre sí, mientras que en épocas de crisis se produjo una autonomización regional (), distanciamiento de cada una de las economías locales. Sin embargo, se vicne comprobando en las últimas monografías regionales que la articulación de los espacios coloniales internos se realizó alrededor de la producción de metales preciosos — que se comportó como punta de lanza en la colonización-, pero también en torno al crecimiento demográfico y la urbanización, ${ }^{20}$. Eric Van Young ha subrayado que la segunda mitad del siglo xvilı se caracterizó por la desarticulación del mercado, la existencia de amplias áreas de producción de subsistencia y, por lo tanto, por la presen. cia de precios muy heterogéneos ${ }^{21}$.

En tercer lugar, hay que analizar detalladamente las cifras que se manejan, pues hasta el momento, y un tanto inexplicablemente, se vienen utilizando unas series que a nuestro parecer no son excesivamente fiables. Durante el gobierno del virrey Revillagigedo II (1789-1794), con motivo de la controversia suscitada sobre las consecuencias de la incorporación de la Nueva España al régimen de comercio libre y de la introducción de las medidas reformistas, se originó una fuerte «batalla» entre los defensores de las «ideas nuevas» y los denominados por aquéllos como «tradicionalistas». El primer grupo se dedicó a construir un fondo documental estadístico probatorio de sus tesis. Reunieron precios, alcabalas, extracciones, tributos, etc., con la intención de bombardear con ellos a los enemigos de las medidas ilustradas ${ }^{22}$. Estas cifras fueron en su mayor parte copiadas por A. de Humboldt -aunque con algunos errores importantes ${ }^{23}$-, divulgándose sin ser criticadas en ningún momento, dada la autoridad reconocida del «sabio» alemán. Posteriormente, el conservador Lucas Alamán las retomaría y haría suyas para demostrar cómo el «orden» colonial era preferible a la «anarquía» ocasionada tras la independencia. Entre el virrey ilustrado, el sabio viajero alemán y el medido conservador fueron «santificando» las cifras originadas al calor de una polémica. Las mismas vienen siendo utilizadas sin apenas crítica por un buen número de historiadores. Comentarlas es una de las finalidades de estas páginas. Quiero subrayar desde un principio que no se van a proponer otras cifras alternativas, sino tan sólo señalar cómo se viene trabajando con unas series que son incorrectas.

\footnotetext{
19 Assadourian (1982); Palerm (1979).

${ }^{20}$ Pérez Herrero (1987).

21 Van Young (1988), p. 221.

"22 Muro (1971).

${ }^{23}$ Pérez Herrero (1988).
} 


\section{A) Las cifras de la producción minera}

Viene siendo tradicional equiparar las cifras de producción de metales preciosos con las de amonedación, derechos de quintos, señoreaje, etc., cuando sabemos que son conceptos diferentes, pues la plata producida (extraída de las minas) no coincidía con la acuñada (marcada con los cuños reales, quintada o diezmada, ya que no toda era fiscalizada), ni con la amonedada (convertida en moneda), ya que una buena parte circulaba en pasta sin quintar como medio universal de pago, siendo posteriormente exportada a los mercados internacionales ${ }^{24}$. Las medidas reformistas borbónicas hicieron que la plata producida se acercara bastante a la plata quintada y amonedada al reducir la circulación interna y el contrabando de la plata en pasta sin quintar. Durante el siglo xvil y la primera mitad del xvin - y más concretamente hasta la década de 1770 - , por lo tanto, no coinciden las cifras de amonedación, quintos y producción. De todo ello se deduce que si se toman las cifras de "amonedación» como indicadores de "producción» sin hacer las rectificaciones necesarias, se está cometiendo un desajuste importante ${ }^{25}$.

Ahora bien, esto no sería demasiado grave si al menos tuviéramos las series fiables completas de la Casa de Moneda para todo el período colonial. Aunque parezca mentira, desde 1535, año en que se funda la Casa de Moneda de la ciudad de México ${ }^{26}$, y 1537, fecha que se da normalmente como inicio de la amonedación en Nueva España, y hasta 1690 , en que comienzan a establecerse registros minuciosos de la plata labrada en la misma, y 1733, en que dicha institución pasa a ser administrada por funcionarios reales en vez de por particulares y cuando comienza a darse noticias oficiales de las acuñaciones totales anuales tanto de la plata como del oro, no se poseen datos exactos o ni siquiera aproximados de la amonedación en el virreinato ${ }^{27}$.

Existen tres series del producto de amonedación de la Casa que generalmente se dan como válidas para el período 1537-1690/1733:

1) La de Manuel Orozco y Berra. El mismo autor expresa que «para sacar un resumen aproximado de la acuñación ha sido indispensable, para los años anteriores a 1690 y 1733 , suponer cantidades y admitir cálculos

${ }^{24}$ Por ejemplo, Coatsworth (1986) y Garner (1980) utilizan, sin hacer ningún tipo de comentario, las series de amonedación de Orozco y Berra o de Humboldt como de producción.

2s Pérez Herrero (1988).

26 Junto con las de Santa Fe, del Nuevo Reino de Granada y la de la villa imperial de Potosí: R. C. de 11 de mayo de 1535, en Fonseca y Urrutia (1845-1853), vol. I, p. 110.

${ }^{27}$ García Martínez (1970). 
que presentan alguna probabilidad" ${ }^{28}$. Las cifras que ofrece no son más que una correción de los datos que se daban como válidos a mediados del siglo xIx. Cuando escribió M. Orozco y Berra se aceptaba que hasta 1690 se habrian acuñado unos 4.000 pesos anuales. Dicho autor supone que «la amonedación aumenta en un país a medida que la población crece y para satisfacer sus necesidades ha menester mayor cantidad de moneda en circulación; en razón de los gastos que la autoridad pública tiene que hacer y según el mayor ensanche que recibe el comercio, sobre todo, cuando en cambio de los efectos no se dan otros, sino que satisface su precio en metales preciosos y todo esto subordinado al producto de las minas». Por todo ello - sigue diciendo dicho autor- la amonedación no pudo ser igual en 1537 que en 1690, sino que ésta debió de ir creciendo paulatinamente según fue aumentando la población y el comercio. Así planteado, llegó a calcular que las acuñaciones de la Casa de Moneda de la ciudad de México serían, «de 1537 a 1548 de millón y medio de pesos; de 1549 a 1558 en dos millones trescientos mil pesos; de 1559 a 1600 en tres millones y medio; de 1601 a 1650 en tres millones y medio; y de 1651 a 1698 en cuatro millones, en cada año y sólo en plata. Pueden pecar estos número por bajos» ${ }^{29}$. Al presentar el propio Orozco y Berra sus series divididas según los años de cada uno de los virreyes, parece a primera vista que son datos medianamente creíbles (véase apéndice 1). Cuando, por el contrario, se hace el gráfico correspondiente, se demuestra que no son más que una mera estimación efectuada, por cierto, partiendo de presupuestos no muy fiables, ya que se olvida que la Nueva España era una colonia, que la plata en su mayor parte se exportaba fuera de sus fronteras y que no toda su economía tenía el mismo nivel de monetización. Como la producción de plata, según Orozco y Berra, dependía de la población -que, por cierto, no se sabe de dónde extrae Orozco y Berra los datos demográficos- y ésta tuvo una inflexión a mediados de siglo, se postula una vez más la «crisis» del siglo xvir (véase tesis de W. Borah).

2) La de A. F. Pradeau. Las cifras que ofrece este autor ${ }^{30}$, y que copian a su vez otros investigadores tales como D. G. López Rosado ${ }^{31}$ o A. R. Barbosa Ramírez ${ }^{32}$, son prácticamente iguales a las que proporciona M. Orozco y Berra, pero presentadas de diferente modo, pues las agrupa en los períodos de los reinados de los reyes españoles. La única diferencia entre ambas series es que A. F. Pradeau da cifras diferentes para las acuñaciones

Orozco y Berra (1853-1855).

29 Orozco y Berra (1853-1855), pp. 937-942; Orozco y Berra (1857). Son las cifras que copia Howe (1949), pp. 453.457.

* Pradeau (1950), p. 133; Pradeau (1957), pp. 61-64.

31 López Rosado (1965), p. 149.

32 Barbosa Ramírez (1977), p. 211. 
de oro de los años 1679,1680 y 1681 , ofreciendo 8.568 pesos, 130.382 pesos y 88.264 pesos, respectivamente.

3) Las de J. González Reina. Presenta datos de «producción» y está especificada en kilogramos, por lo que difícilmente se puede hacer una comparación con las series anteriores. Dicho autor no precisa en qué fuente se basa para obtener los datos que presenta ${ }^{33}$ (véase apéndice 2). Como se puede observar, se trata de estimaciones de bulto en las que se ha presupuesto un porcentaje a priori fijo de crecimiento.

Si comparamos cualquiera de estas tres series con la del derecho de señoreaje -impuesto que en concepto de amonedación se pagaba a la Corona y que quedó estipulado desde 1535 en un real por cada marco amonedado, teniéndose que observar que no hubo cambios en la cuantía del derecho en la época que nos ocupa, por lo que puede servir de indicador de la amonedación ${ }^{34}$-, observamos (véanse gráficos 1 y 2 , en los que se han elaborado medias quinquenales, a fin de evitar los huecos informativos de algunos años) que en nada se parecen las series, ya que la de $M$. Orozco y Berra es casi una línea continua y sin oscilaciones bruscas, mientras que la de señoreaje presenta una curva repleta de picos que se corresponde con lo que conocemos de las tendencias en la producción de metales preciosos para dicha época ${ }^{35}$.

En definitiva, utilizando las cifras de amonedación mencionadas sin establecer previamente alguna rectificación, se hace difícil, en primer lugar, comparar la "producción" minera novohispana de la segunda mitad del siglo xviII con la de la primera, por haber sido eliminada en buena medida la circulación de las platas en pasta sin quintar y haberse logrado una mayor eficiencia fiscal; $y$, en segundo, establecer una relación entre la producción global del xviII con respecto al siglo xviI por carecer de cifras globales ni siquiera medianamente fiables.

Respecto de la extracción de circulante existe también una información contradictoria, pues los reformistas continuamente trataron de demostrar que las medidas innovadoras no habían provocado una sangría de circulante en el virreinato de la Nueva España, mientras que, por su parte, los comerciantes del Consulado de México de forma sistemática denunciaron que el volu-

${ }^{33}$ González Reina (1944), pp. 22, 23.

34 En Castilla se pagaba un real por cada marco como derecho de amonedación. En Indias se estipuló desde un principio (1535) que de cada marco se extrajeran 77 reales, de los que dos, en calidad de "costas», se aplicarían uno al pago de los oficiales reales y el otro para el monarca en calidad de señoreaje. R. C. de 15 de febrero de 1567,26 de octubre de 1613,20 de enero de 1615 y 1 de abril de 1620 . Todas ellas recogidas en Fonseca y Urrutia (1845-1853), vol. I, pp. 11-19. Pasaron a formar la ley 7, tít. 23, lib. 5, de la Recopilación de las leyes de los Reinos de Indias (1681).

${ }_{33}$ Véanse las cifras de producción que da, para Zacatecas, Bakewell (1976). 


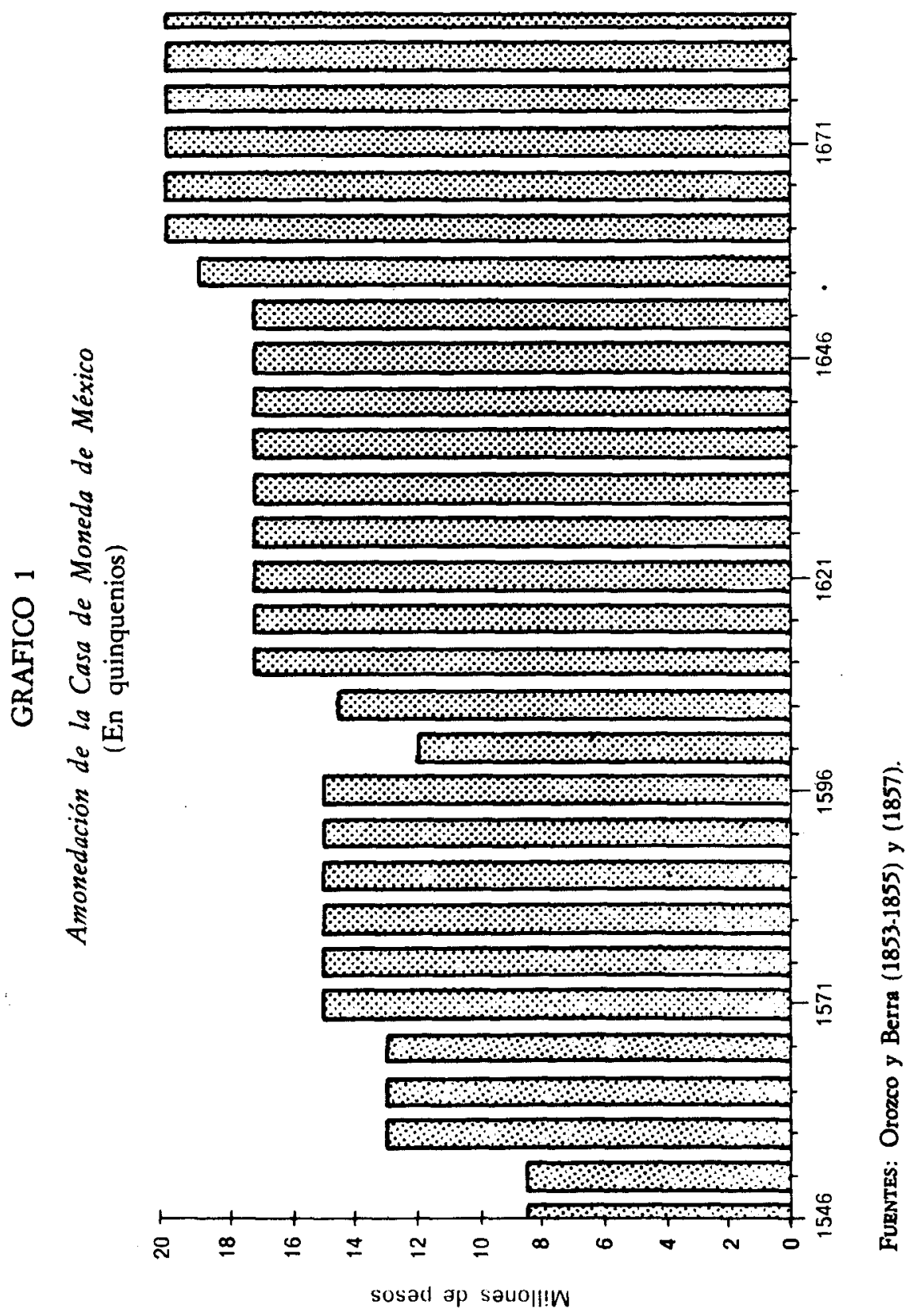




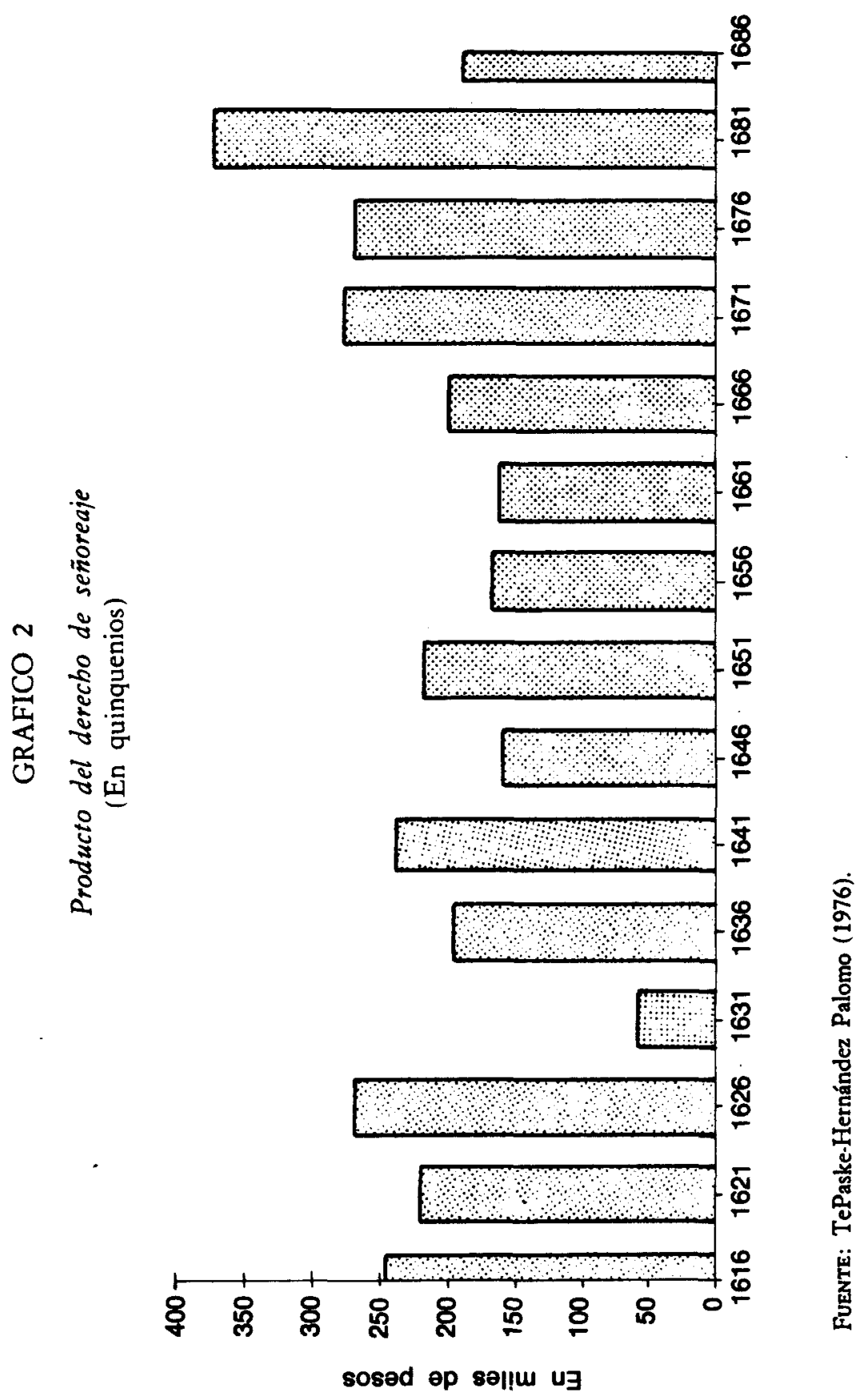


men de las extracciones superaba a finales de la época colonial al de la producción de metales preciosos. Evidentemente si se escogen unas u otras series se tiene un panorama muy diferente de la situación de la Nueva España. Es necesario, por tanto, comparar estas cifras entre sí, así como con las del resto de los indicadores económicos existentes, a fin de poder empezar a acercarnos a la realidad del proceso en cuestión ${ }^{36}$.

\section{B) Las cifras de la producción agricola}

Normalmente para indicar el crecimiento agrícola se suelen utilizar las cifras de los diezmos (véase apéndice 3). Estas series tienen algunos problemas de todos conocidos. Por una parte, en la segunda mitad del siglo xviII aumentaron los arrendamientos del ramo al mejor postor - pasó a ser un negocio lucrativo, aunque lleno de riesgos en sí mismo ${ }^{37}$-, dejando la Iglesia de administrarlo directamente, por lo que el producto del diezmo en algunas regiones puede reproducir más el clima o las esperanzas de ganancia que la producción misma y en otras estar sobrevaluado -en aquellos casos es normal comprobar que el concesionario quebraba ${ }^{38}$-. El diezmo fue utilizado en la segunda mitad del siglo xviri como un fondo sobre el que expedir libranzas. El productor o administrador se comprometía a pagar en el plazo de un año la cantidad adeudada a la Iglesia por concepto de diezmo. Estos vales serían después endosados, circulando como medio de pago ${ }^{39}$.

En segundo lugar, no podemos todavía cuantificar el porcentaje de aumento de la producción agrícola originado por la extensión de la producción sobre áreas hasta entonces incultas o sobre el territorio de las comunidades indígenas -ello dio origen a multitud de tensiones entre las haciendas y las comunidades-, ni el debido a la introducción de innovaciones tecnológicas, claramente utilizado en el Bajío (irrigación, presas) o Morelos (maquinaria de caña de azúcar, abono de campos). Al parecer, el crecimiento en la producción agrícola se debió a una ampliación de los terrenos en cultivo.

${ }^{36}$ Garner (1982), por ejemplo, asentándose en un documento parcial, extrae conclusiones no aceptables. Una crítica exhaustiva de las cifras de extracciones de circulante durante la segunda mitad del siglo xvir puede verse en Pérez Herrero (1988), cap. VIII.

${ }^{37}$ Morín (1979), p. 106.

${ }^{38} \mathrm{El}$ concesionario recaudaba el producto $y$, en una fecha fija, entregaba la suma estipulada en el contrato, que generalmente duraba cinco años. La asignación de la concesión requería de un conjunto de cálculos: a) anticipación del volumen aproximado del diezmo; b) previsión del nivel de los precios, y c) cálculo de los gastos efectuados por el concesionario. Un miembro del Tribunal de Cuentas señaló en 1784 que la concesión de la recaudación del diezmo era uno de los medios de amasar un capital, y calculó la ganancia de este tipo de empresa en un 25 por 100. Morín (1979), p. 106.

${ }^{39}$ Rabell (1985), pp. 48, 49. 
En tercer lugar, hay que añadir que había ciertas producciones agrícolas que no estaban sujetas al diezmo. Hay muchas dudas y contradicciones, según unas $\mathrm{u}$ otras zonas, pero al parecer el indígena pagaba diezmo del trigo, cebada, garbanzo, haba, lenteja, arroz y demás «semillas de Castilla», estando exento de hacerlo de maíz, frijol, grana, cacao, algodón, chile, pulque y demás producciones «de la tierra» ${ }^{40}$.

En cuarto lugar, este impuesto puede reproducir el incremento de los precios, antes que el de la producción. En épocas de malas cosechas suben los precios y en buenas bajan. Por tanto, hay que deflactar los diezmos. Para ello, sin embargo, no contamos con series de precios completas de varios productos agrícolas. Las de E. Florescano se refieren exclusivamente al maíz -recuérdese que precisamente el maíz no estaba sujeto al pago del diezmo por parte de los indígenas-y son precios del pósito y la alhóndiga de la ciudad de México, por lo que hay problemas para saber hasta qué punto eran precios de consumo o precios de mercado y si es posible por tanto deflactar con ellos los diezmos de otras regiones alejadas, al no existir un perfecto mercado nacional ${ }^{41}$. R. L. Garner ha realizado un intento de hallar el comportamiento general de los precios en la Nueva España durante el siglo XVIII, incorporando a las series del maíz de E. Florescano algunos datos de otros productos - trigo, harina, frijoles, etc.- procedentes de varias regiones - Bajío, Guadalajara, Michoacán, Oaxaca (recoge los trabajos de Borah, Gibson, Florescano, Brading, Hurtado, Morín, Tovar Pinzón, Hamnett y Van Young)-. Según el mismo autor, al parecer, los precios del maíz subieron fuertemente en la segunda mitad del siglo xviII, con respecto a la primera ${ }^{42}$. Ahora bien, ¿es posible hablar de un comportamiento general en los precios para todo el virreinato cuando no contamos con un mercado nacional? ${ }^{43}$. Parecería que antes habría que realizar un análisis de la geografía de los precios.

A corto plazo, los diezmos presentan un problema adyacente. La cosecha del año, pongamos por caso, 1770 se venía en su mayor parte en el año de 1771 a los precios de 1771 . Si el año de 1770 había sido bueno, lo normal era que hubieran bajado los precios. Al hacendado, por una parte, le interesaba vender la cosecha en el año siguiente de 1771 , posiblemente un año

40 Medina Rubio (1983), pp. 73, 74.

"Lindo Fuentes (1980), pp. 273-289, es partidario de la integración económica virreinal y, por lo tanto, de la posibilidad de emplear un indice de precios general. Por el contrario, Van Young (1988) es partidario de pensar que la Nueva España no había llegado a funcionar como un mercado nacional. Según esto, no se podría emplear un índice general de precios para realizar las diferentes conversiones de precios corrientes a precios constantes en las distintas regiones.

42 Garner (1985).

43 Van Young (1988) argumenta la falta de integración económica de la Nueva España. 
peor $\mathrm{y}$, por tanto, de precios más altos, pero, por otra, se veía castigado con el pago, en términos totales, de una mayor cantidad de diezmo. Los vales, realmente un crédito de un año, solucionaban el problema del pago de las obligaciones fiscales a los productores en tiempos de «vacas flacas». El hacendado podía disponer de capital para reinvertir en su empresa. En definitiva los ingresos por diezmos no reflejan a corto plazo las bruscas oscilaciones en la producción agrícola ${ }^{44}$.

Respecto a los precios existen bastantes preguntas por resolver, por lo que no es tan sencillo realizar las deflaciones: a) ¿Los artículos de importación siguen las mismas oscilaciones que los agrícolas de producción interna? Todo parece indicar que no, que están regidos por coyunturas diferentes. El problema es que no tenemos aún series de precios completas de estas mercancías y de sus variaciones según se iban interiorizando en la geografía virreinal y alejándose consecuentemente de los puertos de entrada-salida ${ }^{45}$. b) El maíz es un producto inelástico con un comportamiento diferente en el consumo del de, por ejemplo, los textiles ${ }^{46}$. c) Sabemos que los hacendados preferían no lanzar cantidades grandes de maíz al mercado que hicieran bajar los precios ${ }^{47}$. Si esto es cierto, el precio de los cereales en la larga duración - no así en la corta y la media, donde los efectos climatológicos son de capital importancia - no dependería del libre juego oferta (producción)/demanda (población urbana no autosuficiente), sino de la segunda, a la que se sumaba el control monopólico de la comercialización de los cereales. Para evitarlo, la Corona se valió del mecanismo de los pósitos y de las alhóndigas. Los precios, entonces, seguirían las oscilaciones demográficas, en este caso compuestas por el crecimiento poblacional y la urbanización (migración campo-ciudad) ${ }^{48}$.d) ¿Qué espacio ocupa la economía monetizada? ¿Cuál la de autoconsumo? ¿Qué papel ocupan los precios?

Teniendo en cuenta todo este cúmulo de dudas y problemas, si deflactamos las series conocidas de diezmos de los obispados de México, Guadalajara, Oaxaca, Valladolid, Puebla y Durango ${ }^{49}$, observamos que, a excepción del obispado de México, se obtienen curvas bastante planas o con un aumento leve. Diferentes monografías regionales, sin embargo, han rectificado esta visión, ya que las regiones de Guadalajara y el Bajío se ha comprobado que

4 Rabell (1985), p. 48.

${ }_{45}$ Pérez Herrero (1984). Romano (1986) plantea la existencia de tres movimientos de precios para el siglo xviII: a) los de los artículos de producción local; b) los de origen americano, y c) los de origen europeo.

4s Salvucci (1987), pp. 150-153.

47 Suárez (1985) habla de sobreproducción en toda la historia de la Nueva España. Idem, Artís Espriú (1986). Parece una conclusión demasiado rotunda.

4' Garner (1985).

49 «Ensayo Apologético...» (1975), pp. 368-370. Las mismas cifras las copia Humboldt (1978). 
ampliaron notablemente su producción agrícola ${ }^{50}$. Las series de diezmos, en conclusión, nos ofrecen una imagen que no se corresponden fielmente con los resultados de las diferentes investigaciones regionales construidas con base en otros indicadores económicos.

\section{C) Las cifras de los intercambios}

Los defensores de las ideas reformistas borbónicas continuamente citaban los efectos benéficos de las mismas, subrayando la enorme subida que se había producido en los ramos de alcabalas y aduanas del virreinato, al pasarse de 19.844.053 pesos de recaudación de alcabalas entre los años de 1765-1777 a 42.628.340 pesos entre 1778-1790; y de 6.661 .963 pesos en el ramo de aduanas de México entre 1766-1778 a 9.462 .014 pesos entre 1779-1791 (véase apéndice 4). Estas cifras, confeccionadas por el grupo de trabajo de Revillagigedo, han sido objeto de innumerables críticas. El problema básico es si pueden ser utilizadas sin más como indicadores económicos de la actividad mercantil, reflejo del movimiento de la producción. Que las rentas subieron en la segunda mitad del siglo xviri es algo que no se puede poner en duda después de los trabajos de $\mathrm{H}$. Klein y $\mathrm{J}$. TePaske ${ }^{51}$. Ahora bien, inferir de dichas cifras que el movimiento mercantil se multiplicó por tres o por cuatro es algo que merece algunos comentarios.

No hace mucho tiempo J. C. Garavaglia y J. C. Grosso pusieron de manifiesto que el incremento de la fiscalidad sobrepasó al crecimiento de la producción ${ }^{52}$. En primer lugar, la presión fiscal creció no sólo verticalmente, al aumentar las obligaciones fiscales de los contribuyentes, sino también horizontalmente, al incorporarse nuevos sectores de población que antes, o bien por exenciones o por descuido de la administración, habían quedado fuera de la maquinaria de la Real Hacienda. El contrabando se redujo en buena medida. Las alcabalas subieron de un 2 por 100 hasta un 8 por 100 , según las épocas y regiones, para pagar la construcción de caminos, la vigilancia, las guerras atlánticas, el aumento de la avería o los "préstamos patrióticos" concedido por el Consulado ${ }^{53}$.

En segundo lugar, mejoró ostensiblemente la administración, evitándose

so Van Young (1987).

${ }^{31}$ Klein (1985), p. 592, acepta que «el movimiento fiscal refleja los cambios fundamentales de la economia». De iguales presupuestos se parte en Klein (1986), TePaske y Hernández Palomo (1976) y TePaske y Klein (1986) (sólo ha aparecido el vol. I, relativo a las Cajas de Acapulco, Arizpe, Bolaños, Campeche, Chihuahua, Durango, Guadalajara, Guanajuato y Mérida). Véase TePaske (1986).

${ }^{32}$ Garavaglia y Grosso (1985).

${ }^{53}$ Pérez Herrero (1988); Pastor (1977). 
los fraudes en la recaudación y los «errores» en la contabilidad. El Consulado de México desde 1754 dejó de administrar el ramo de alcabalas. El gremio, a través de su apoderado en la Corte, ofreció al monarca fuertes sumas en metálico como «anticipo», a fin de conseguir la renovación del antiguo encabezamiento del ramo; esgrimió toda clase de argumentos - si había sido «blando» en el cobro de las alcabalas, había sido por favorecer a algunos contribuyentes e impedir con una excesiva presión la subida de los precios y la paralización en las ventas-, pero... nada consiguió. El gobierno sabía muy bien que extraería más beneficios administrando directamente el ramo que aceptando las sumas ofrecidas por los propios comerciantes. $\mathrm{Si}$ aquéllos tanto peleaban por mantener las alcabalas en sus manos era porque obtenían pingües ventajas. Desde luego, era de esperar que los miembros del Consulado no saldasen puntualmente el pago de las alcabalas. La realidad fue inobjetable. En un año de administración directa por la Corona los ingresos del ramo se duplicaron ${ }^{54}$.

En definitiva, las variaciones de los montos de las alcabalas no necesariamente reflejan las fluctuaciones del intercambio, sino que muchas veces pueden no ser más que un indicador de las variaciones de la presión fiscal. Entre 1750 y 1776 el aumento de los ingresos de la Real Hacienda fue moderado en comparación con el período 1777-1810, donde se llegó a un incremento del 155 por 100 . Ahora bien, este aumento no fue ni general ni homogéneo, ya que hubo sectores, como la minería, o regiones - zona fronteriza norteña- que gozaron de exenciones importantes ${ }^{55}$.

A todo ello habría que añadir que, por ser unos impuestos sobre el valor de los intercambios, el mismo proceso inflacionario hizo que subieran los montos totales. Habría, una vez más, que deflactar los totales anuales de las alcabalas, pero... nos encontramos con que no tenemos series completas de precios de las mercancías de importación y las de producción local comercializadas por el interior del virreinato. A ello habría que añadir que el pago de la alcabala, el almojarifazgo o la averia no se efectuaba sobre el precio de mercado, sino al por mayor. Es sorprendente que todavía se sigan dando cifras de importación-exportación por los puertos de Veracruz o Acapulco por el valor total de las mercancías sin hacer las deflaciones necesarias ni los comentarios pertinentes a la información contenida en las Balanzas comerciales, fuente de la que suelen partir todos los estudios ${ }^{56}$. Hay que subrayar que esta fuente hay que manejarla con mucho cuidado, ya que las cantidades que anotan están muy elaboradas para encubrir el propio contrabando que

${ }^{44}$ Archivo Histórico de Hacienda (México), 635-5, 635-8, 550-54; Fonseca y Urrutia (1845-1853), vol. I, pp. 36-52.

ss Garavaglia y Grosso (1985), pp. 7, 22-24.

s6 Ortiz de la Tabla (1978). 
hacían los miembros del Consulado veracruzano. En ellas los valores de las importaciones están anotados según los «precios que tenían en la plaza de Veracruz, en los cuales se incluían ya las grandes ganancias que en virtud del monopolio obtenían entonces los importadores» ${ }^{57}$, por lo que las sumas representadas respecto a las importaciones están desmesuradamente infladas. Esta diferencia de precios que el propio Miguel Lerdo de Tejada calcula en un 25 por 100 , rebajada de la cifra total de las importaciones que de 1796 a 1820 se hicieron por el puerto de Veracruz, produciría anualmente una ganancia muy cercana a tres millones de pesos.

\section{D) Las citras de población}

Las cifras de población también forman parte de la polémica. Los reformistas argumentaron que el «crecimiento económico» inducido por la introducción de las medidas innovadoras, entre otras cuestiones, ocasionó un aumento demográfico, visible claramente en una elevación del ramo de tributos (véase apéndice 5). Esta interpretación, en la actualidad, sigue teniendo claros defensores. H. S. Klein afirma que «el desarrollo económico general estimuló a su vez el incremento demográfico. En el curso de este siglo xviII la población novohispana se duplicó, alcanzando la cifra de seis millones de habitantes» ${ }^{58}$.

Ahora bien, ¿el crecimiento económico posibilitó un aumento demográfico o fue éste el que impulsó aquél? Todavía no tenemos una respuesta definitiva, pero de momento los historiadores están buscando y retocando las cifras de población que invariablemente se venían manejando. Lo que parece indudable es que no se pueden seguir utilizando, sin crítica previa, las cifras generales de población del virreinato manejadas hasta la fecha (véase apéndice 6). Las del censo de Revillagigedo de 1793 no son todo lo perfectas que pudieran parecer; faltan datos de las Intendencias de Veracruz, Coahuila y Guadalajara; y, al parecer, la población, cuando se hizo el censo, temiendo que se utilizara con fines fiscales, «escondió" datos para evitar un aumento en la presión de la maquinaria de la Real Hacienda. Las cifras de Humboldt de 1803 son una mera estimación del aumento habido entre el censo de Revillagigedo y la fecha de su análisis. Lo que hace Humboldt es limitarse a calcular una tasa general de crecimiento para todo el virreinato - por cierto un tanto dudosa, pues en diferentes partes de sus

st Lerdo de Tejada (1967), pp. 25-27. Potash (1953) denunció ya hace bastante tiempo las tremendas irregularidades de los cómputos de Lerdo con respecto al valor de las im. portaciones procedentes de Inglaterra.

${ }^{38}$ Klein (1985), p. 562. 
trabajos pasa de un 3 a un 2 o un 1 por 100 anual-y porcentuar la población resultante con los totales conocidos de cada intendencia. Aplica tasas fijas de crecimiento para todas las intendencias. Por otra parte, cuando copia las cifras del censo de Revillagigedo de 1793 comete errores. Las sumas no cuadran con los totales parciales. Sobrestima el número de europeos: da una cifra de 70/80.000, cuando el resto de los autores ponen $7 / 8.000$ (parece que no se dio cuenta y añadió un cero de más). Hay contradicciones en su texto. Subestima el número de indígenas y sobrestima el de mestizos. Calcula erróneamente un total de $2.335 .628 \mathrm{Km}^{2}$ cuando, según datos modernos, a fines del siglo xviri la Nueva España alcanzó los $4.146 .483 \mathrm{Km}^{2}$. En consecuencia, las densidades de población que da han de tomarse con total cautela -al parecer el error está en las dimensiones de las Provincias Internas, más que en las de los espacios centrales del virreinato-. Las cifras de Navarro y Noriega, que no se basa en las del censo de Revillagigedo, son las más fiables, aunque no dejan de presentar algún problema, como el de presuponer una tasa de crecimiento fijo para todas las regiones del virreinato ${ }^{59}$. Las de Villaseñor son incompletas, haciéndose difícil cualquier comparación.

Ante este espectáculo de falta de datos fiables, se ha comenzado a trabajar más seriamente en demografía regional. Hasta la fecha, y aun sin contar con todo el mapa completo del virreinato, se ha comprobado la falsedad de la tesis del fuerte crecimiento demográfico a finales del siglo xvirI como consecuencia del reformismo borbónico ${ }^{60}$. En contra de lo hasta ahora interpretado, fue a finales del siglo xvil cuando se dio el fuerte impulso demo. gráfico, observándose incluso a finales del xvin tasas de crecimiento en algunas regiones negativas. Si esta interpretación se confirma en los próximos años, como parece muy probable, el reformismo borbónico no sería entonces promotor del crecimiento demográfico, sino, por el contrario, beneficiario del mismo.

\section{E) Las cifras de los ingresos de la Real Hacienda}

Un argumento que se viene repitiendo constantemente es que en la segunda mitad del siglo xviı los ingresos de la Real Hacienda se multiplicaron hasta por diez (véase apéndice núm. 7$)^{61}$. Las cifras que se manejan son

${ }^{59}$ Lerner (1968). Humboldt se equivocó también cuando afirmó que en el censo de Revillagigedo de 1793 no se recopilaron los datos de la intendencia de Guadalajara. Lo único que pasó fue que se enviaron con retraso. Pueden verse ahora publicados en Menéndez Valdés (1980).

${ }^{\infty}$ Una buena síntesis de los trabajos existentes véase en Rabell (1984).

${ }^{61}$ Klein (1985). 
claras, pero necesitan algunos comentarios. En primer lugar, al igual que las otras series comentadas, hay que deflactarlas para poder comparar los ingresos de principios del xuIII con los de finales de la época colonial. En este caso los precios del maíz del pósito y la alhóndiga de México podrían servir como un indicador. Haciéndolo se puede comprobar que estos ingresos se reducen en buena medida, ya que fue precisamente durante los años finales del siglo xvirr cuando el proceso inflacionario fue más intenso.

En segundo lugar, si se emplean como indicadores económicos, se hace problemático comparar las cifras de los diferentes ramos de la época de los Borbones con las de los Austrias, debido a que, con motivo del plan reformista dieciochesco, se logró una mayor eficiencia en la Administración.

En tercer lugar, hay que tener presente que si subieron las rentas en su conjunto, no todos los ramos lo hicieron por igual. Los ingresos procedentes de las actividades mineras crecieron durante el siglo xviri tan sólo entre un 20 y un 27 por 100. Para los últimos años del siglo xvin los ingresos fiscales procedentes del comercio y la agricultura superaron a los de la minería, acabando el comercio por ser la fuente más importante de entradas de la Real Hacienda. Los impuestos al consumo sobre productos de monopolio real - tabaco, naipes, nieve, papel sellado, pólvora- crecieron de forma muy rápida. Finalmente, hay que subrayar que una categoría fiscal que hasta entonces habia tenido un papel insignificante en el marco del ingreso total percibido por la Corona, la de los empréstitos voluntarios y forzosos, comenzó a crecer de forma inusitada, llegando a convertirse a finales del período colo. nial en la parte medular de las rentas reales. Las guerras contra Inglaterra (1796-1802 y 1804-1807) obligaron a tomar medidas extraordinarias, tales como la nacionalización de los bienes de la Iglesia y la apertura de empréstitos forzosos o voluntarios y la imposición de contribuciones extraordinarias de guerra.' Hay que subrayar, sin embargo, que no todos estos empréstitos forzosos fueron cobrados. En definitiva, parece claro que en los últimos años de la colonia las rentas subieron, pero no como reflejo de la producción, sino como consecuencia de una mayor presión fiscal. Si la población en su conjunto - utilizando los datos existentes- se multiplicó por cinco entre 1742 y 1810, los ingresos reales se multiplicaron por diez nominalmente y por siete en términos reales ${ }^{62}$.

En suma, se comprueba que: a) parece claro que si aceptamos la visión tradicional de una Nueva España borbónica inscrita en una tendencia general de "crecimiento", como los «reformistas» se empeñaron en intentar demostrar, las cifras oficiales existentes no presentan muchos problemas, pero si analizamos los territorios americanos desde una óptica interna más compleja

${ }^{62}$ Klein (1985); TePaske (1986). 
y polifacética como se ha comenzado a trabajar, comprobamos que es necesario utilizar otros indicadores; $b$ ) se han venido aceptando y repitiendo sistemáticamente sin una crítica previa unos datos originados a finales del siglo xviII y comienzos del siglo xix a la sombra de la polémica que enfrentó a los «reformistas» contra los «monopolistas» y a los liberales contra los conservadores; c) la propia repetición de las mismas series ha ido creando un clima de aceptación generalizado que es necesario desmontar; d) no se pueden tomar las cifras fiscales como indicadores económicos sin realizar previamente las rectificaciones necesarias; $e$ ) parece que es bastante prematuro hacer cálculos con cierto margen de fiabilidad del PIB o de la renta per capita, como se ha puesto últimamente de moda después de los trabajos de J. H. Coatsworth ${ }^{63}$, y $f$ ) es necesario, ante la ausencia de un mercado nacional totalmente constituido, trabajar dentro de marcos regionales más restringidos y no con cifras generales para todo el virreinato. Evidentemente, y mientras no tengamos otras cifras mejores que las actuales, tendremos que seguir manejando las existentes; ahora bien, conscientes de los problemas que encierran y de lo mediatizadas que resultarán sus conclusiones.

${ }^{63}$ Coatsworth (1978). Los datos y procedimientos empleados para calcular el ingreso nacional mexicano - dice Coatsworth- "pueden ser obtenidos pidiéndoselos al autor» (p. 173). Un resumen de sus posiciones véase en Coatsworth (1988). 


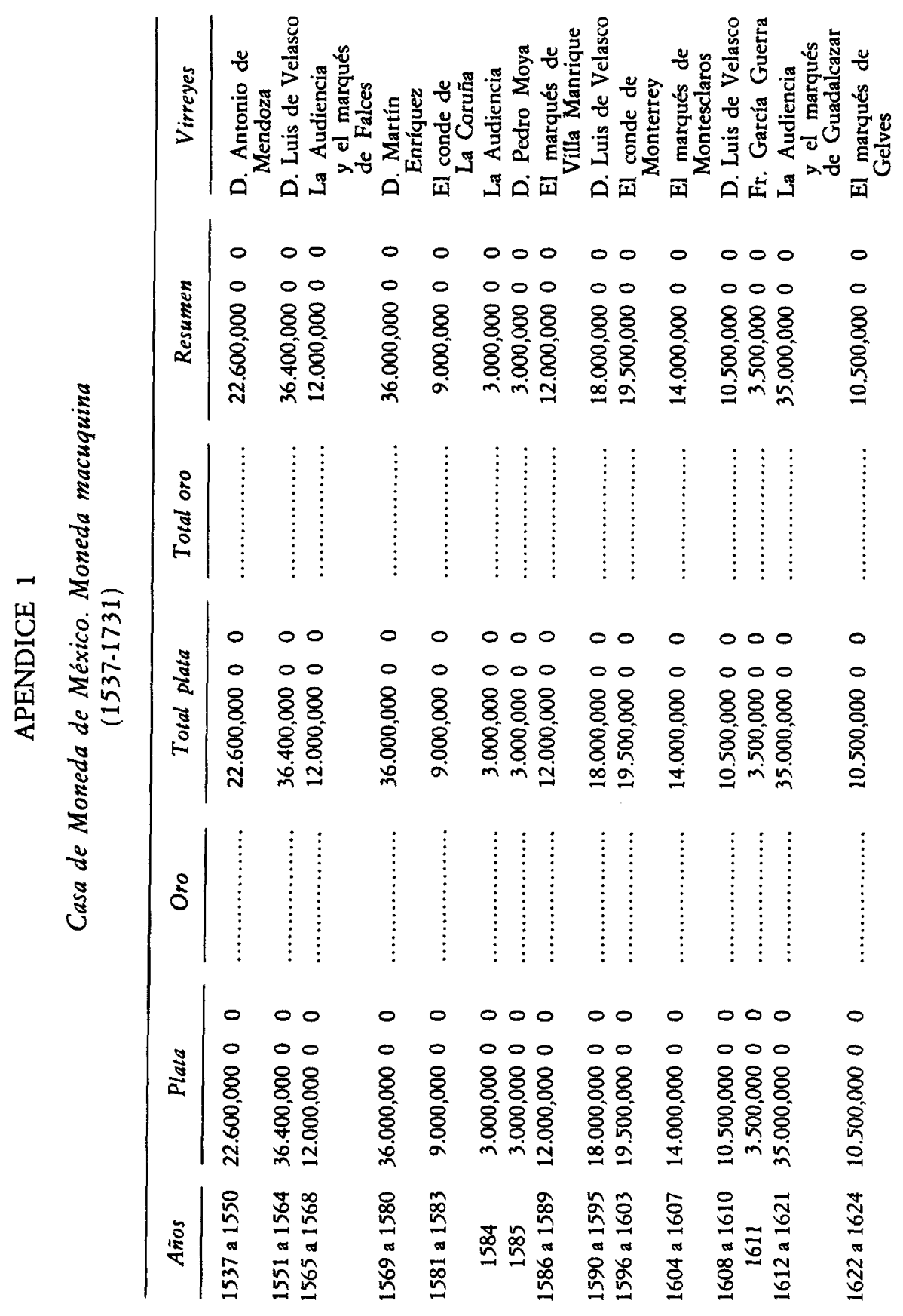




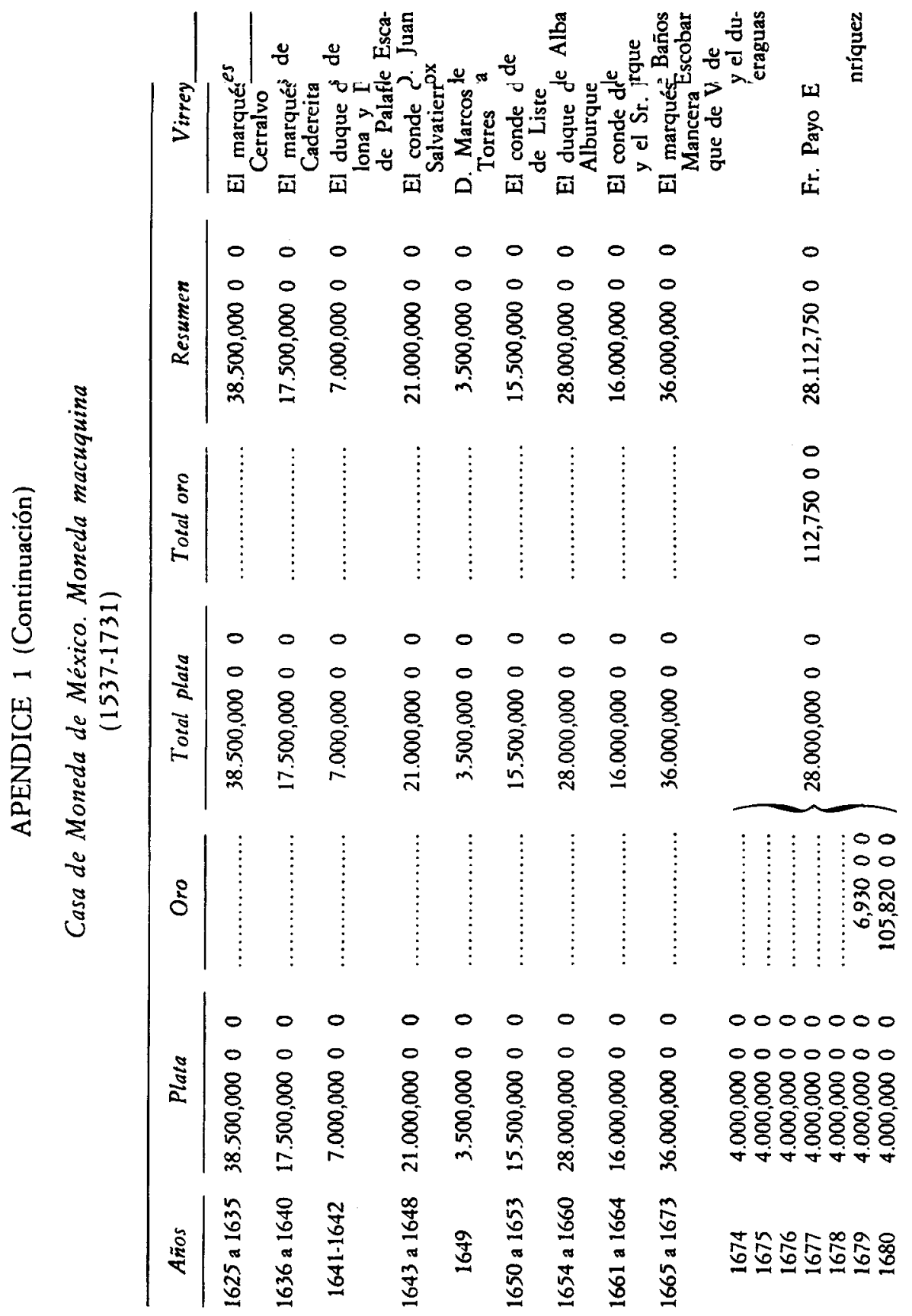




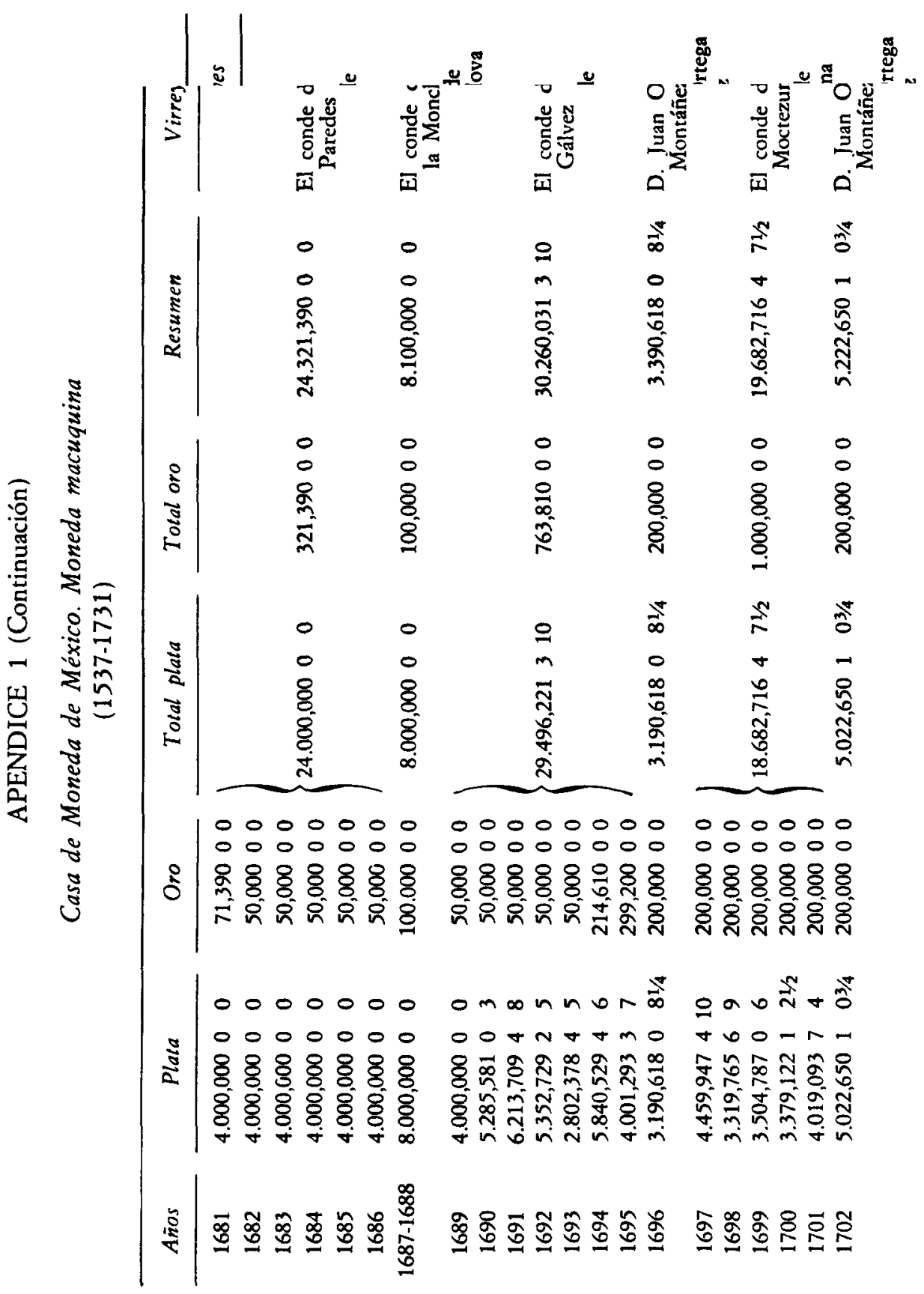




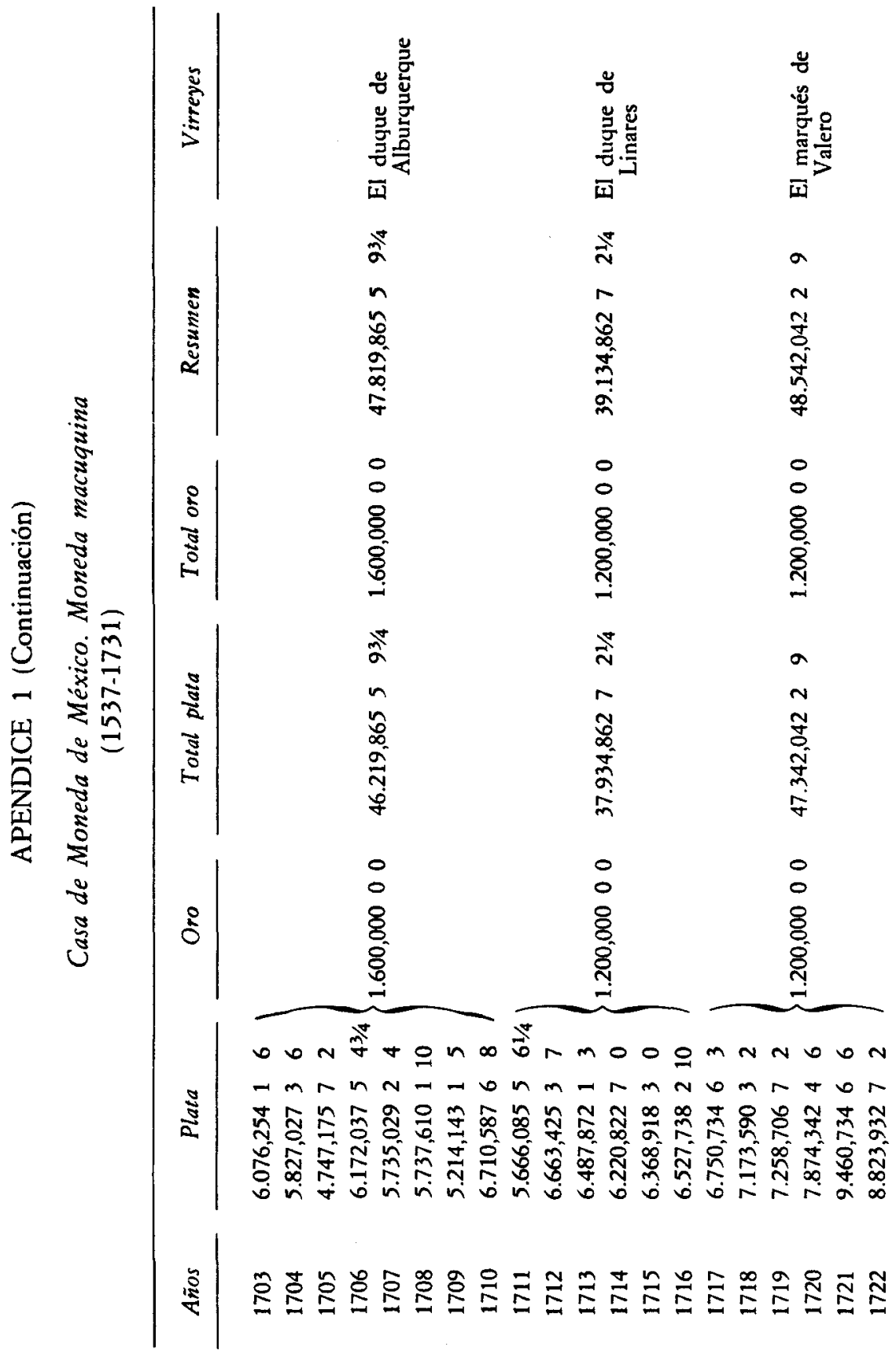




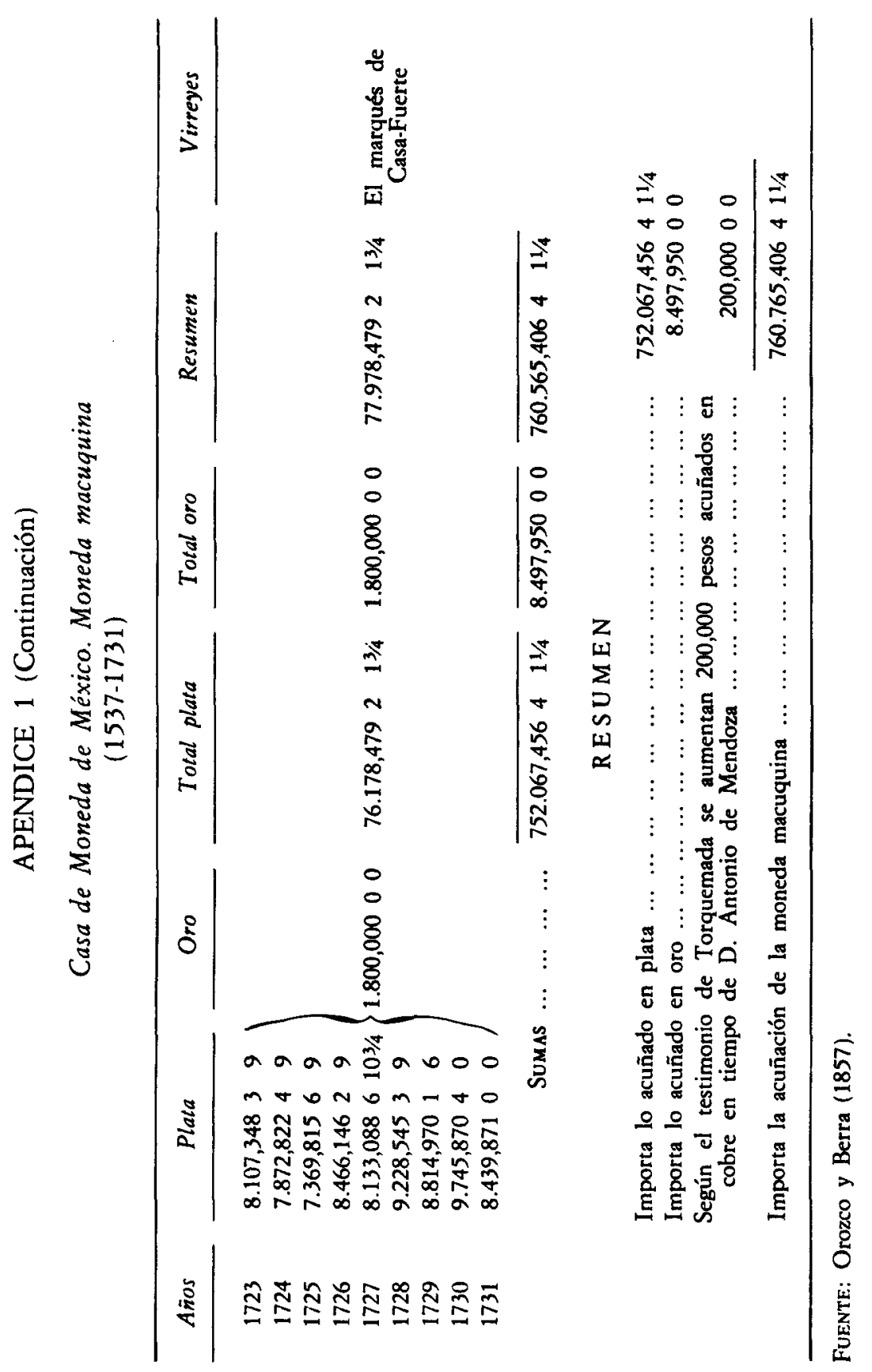




\section{APENDICE 2}

Producción de plata en México, según González Reina (1944)

\begin{tabular}{|c|c|c|c|}
\hline$A \tilde{n} o s$ & Kilogramos & $A \tilde{n} o s$ & Kilogramos \\
\hline 1521.1544 & 82.000 & $1621-1640$ & 1.764 .000 \\
\hline $1545-1560$ & 240.000 & $1641-1660$ & 1.904 .000 \\
\hline $1561-1580$ & 1.004 .000 & $1661-1680$ & 2.042 .000 \\
\hline $1581-1600$ & 1.486 .000 & $1681-1700$ & 2.204 .000 \\
\hline $1601-1620$ & 1.634 .000 & $1701-1720$ & 3.276 .000 \\
\hline
\end{tabular}

\section{APENDICE 3}

Gruesa de diezmos de México

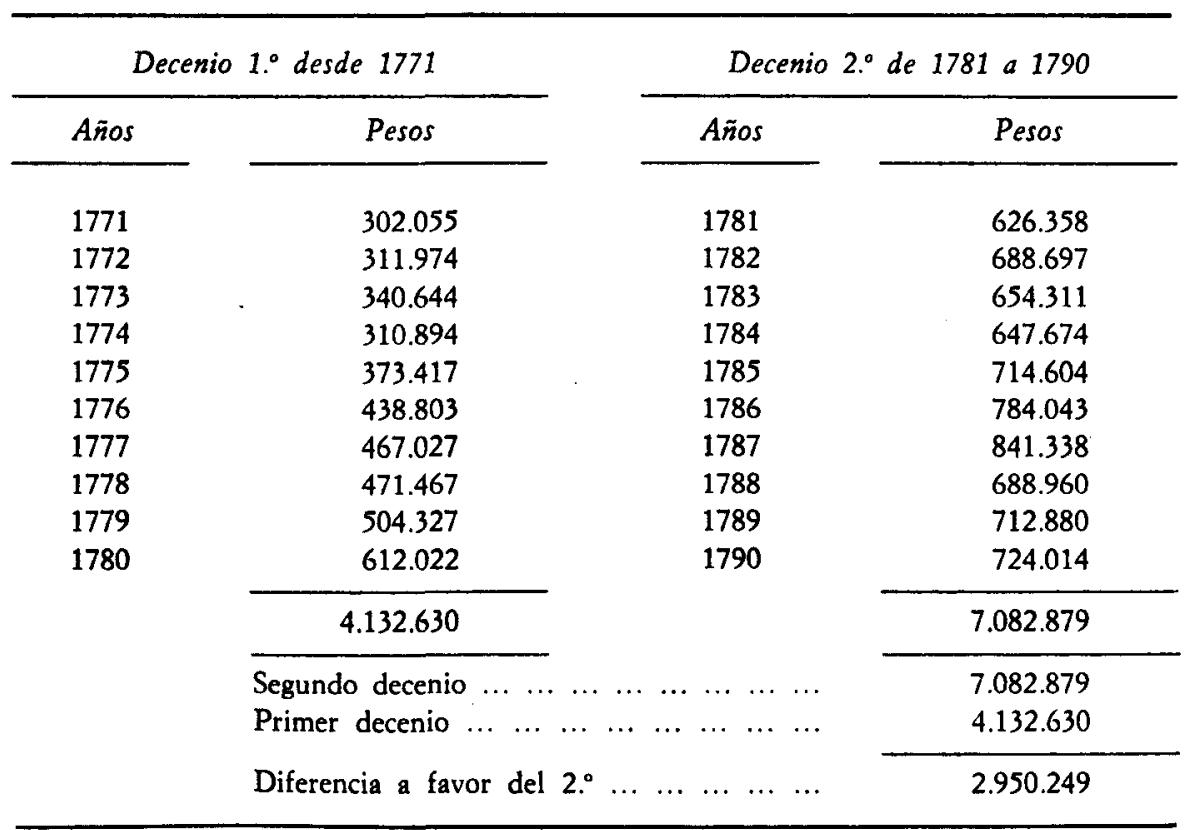


APENDICE 3 (Continuación)

Gruesa de diezmos de Puebla

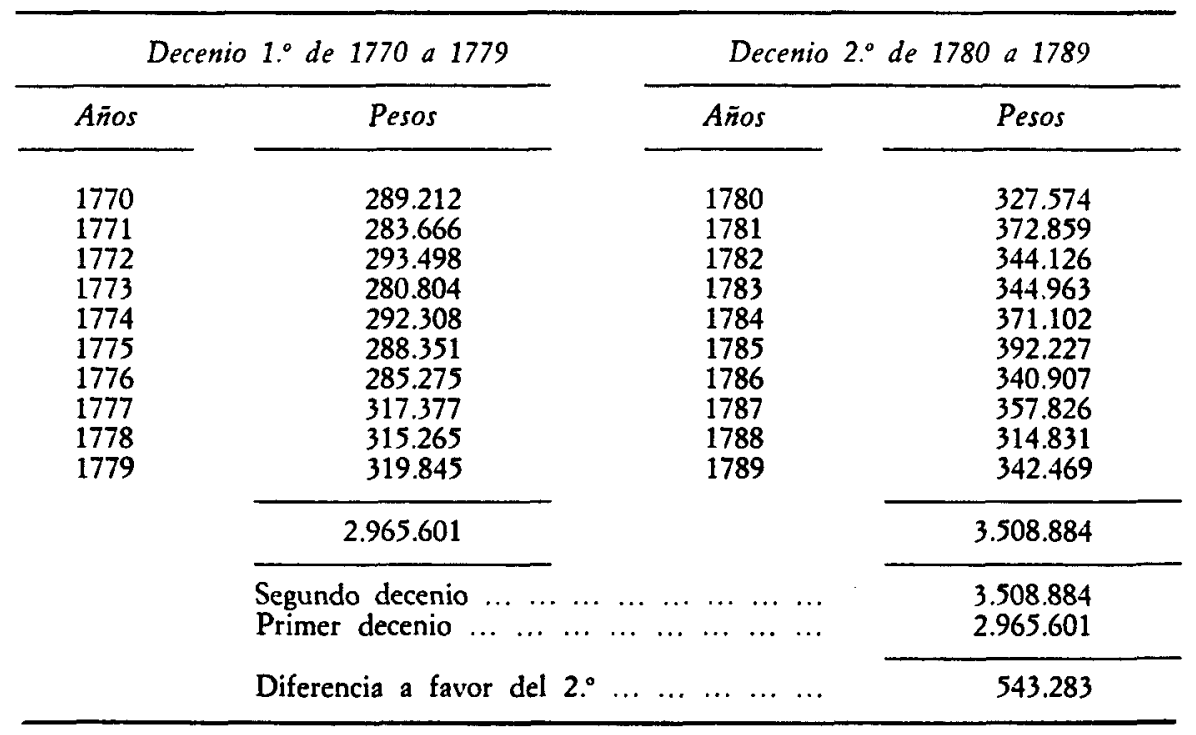

Gruesa de diezmos de Valladolid

\begin{tabular}{|c|c|c|c|}
\hline \multicolumn{2}{|c|}{ Decenio $1 .^{\circ}$ de 1770 a 1779} & \multicolumn{2}{|c|}{ Decenio $2 .^{\circ}$ de 1780 a 1789} \\
\hline Años & Pesos & Años & Pesos \\
\hline \multirow[t]{4}{*}{$\begin{array}{l}1770 \\
1771 \\
1772 \\
1773 \\
1774 \\
1775 \\
1776 \\
1777 \\
1778 \\
1779\end{array}$} & $\begin{array}{l}253.000 \\
283.000 \\
265.700 \\
276.600 \\
278.000 \\
250.000 \\
264.300 \\
265.400 \\
291.200 \\
283.000\end{array}$ & $\begin{array}{l}1780 \\
1781 \\
1782 \\
1783 \\
1784 \\
1785 \\
1786 \\
1787 \\
1788 \\
1789\end{array}$ & $\begin{array}{l}307.200 \\
292.700 \\
299.400 \\
324.200 \\
308.300 \\
327.000 \\
330.100 \\
359.200 \\
342.400 \\
348.900\end{array}$ \\
\hline & 2.710 .200 & & 3.239 .400 \\
\hline & $\begin{array}{lllllll}\text { Segundo decenio } & \ldots & \ldots & \ldots & \ldots & \ldots \\
\text { Primer decenio } & \ldots & \ldots & \ldots & \ldots & \ldots\end{array}$ & $\begin{array}{lll}\cdots & \cdots & \cdots \\
\cdots & \cdots & \cdots\end{array}$ & $\begin{array}{l}3.239 .400 \\
3.710 .200\end{array}$ \\
\hline & Diferencia a favor del $20^{\circ} \ldots \ldots$ & $\begin{array}{llll} & \ldots & \cdots & \ldots\end{array}$ & 529.200 \\
\hline
\end{tabular}


APENDICE 3 (Continuación)

Gruesa de diezmos de Guadalajara

\begin{tabular}{|c|c|c|c|}
\hline \multicolumn{2}{|c|}{ Decenio $10^{\circ}$ de 1771 a 1780} & \multicolumn{2}{|c|}{ Decenio $20^{\circ}$ de 1781 a 1790} \\
\hline Años & Pesos & $A \tilde{n} o s$ & Pesos \\
\hline \multirow[t]{4}{*}{$\begin{array}{l}1771 \\
1772 \\
1773 \\
1774 \\
1775 \\
1776 \\
1777 \\
1778 \\
1779 \\
1780\end{array}$} & $\begin{array}{l}164.220 \\
175.660 \\
191.798 \\
192.084 \\
195.103 \\
112.136 \\
183.442 \\
231.356 \\
224.153 \\
219.772\end{array}$ & $\begin{array}{l}1781 \\
1782 \\
1783 \\
1784 \\
1785 \\
1786 \\
1787 \\
1788 \\
1789 \\
1790\end{array}$ & $\begin{array}{l}231.259 \\
211.375 \\
290.595 \\
306.010 \\
304.898 \\
285.714 \\
190.917 \\
213.538 \\
316.310 \\
228.492\end{array}$ \\
\hline & 1.889 .724 & & 2.579 .108 \\
\hline & $\begin{array}{lllllll}\text { Segundo decenio } & \ldots & & & & & \\
\text { Primer decenio } & \ldots & \ldots & \ldots & \ldots & \ldots & \ldots\end{array}$ & $\begin{array}{lll}\cdots & \cdots & \cdots \\
\cdots & \cdots & \cdots\end{array}$ & $\begin{array}{l}2.579 .108 \\
1.889 .724\end{array}$ \\
\hline & Diferencia a favor del $20^{\circ} \ldots .$. & $\begin{array}{lll}\ldots & \ldots & \ldots\end{array}$ & 689.384 \\
\hline
\end{tabular}

Gruesa de diezmos de Oaxaca

\begin{tabular}{|c|c|c|c|}
\hline \multicolumn{2}{|c|}{ Decenio $10^{\circ}$ de 1771 a 1780} & \multicolumn{2}{|c|}{ Decenio $20^{\circ}$ de 1781 a 1790} \\
\hline$A \tilde{n} o s$ & Pesos & Años & Pesos \\
\hline \multirow[t]{4}{*}{$\begin{array}{l}1771 \\
1772 \\
1773 \\
1774 \\
1775 \\
1776 \\
1777 \\
1778 \\
1779 \\
1780\end{array}$} & $\begin{array}{l}68.718 \\
64.648 \\
66.635 \\
68.159 \\
69.667 \\
87.294 \\
74.423 \\
57.372 \\
85.201 \\
73.857\end{array}$ & $\begin{array}{l}1781 \\
1782 \\
1783 \\
1784 \\
1785 \\
1786 \\
1787 \\
1788 \\
1789 \\
1790\end{array}$ & $\begin{array}{l}87.533 \\
88.769 \\
93.599 \\
86.568 \\
79.562 \\
76.057 \\
75.818 \\
90.878 \\
97.011 \\
87.440\end{array}$ \\
\hline & 715.974 & & 863.237 \\
\hline & $\begin{array}{lllllll}\text { Segundo decenio } & \ldots & \ldots & \ldots & \ldots & \ldots \\
\text { Primer decenio } & \ldots & \ldots & \ldots & \ldots & \ldots\end{array}$ & $\begin{array}{lll}\cdots & \cdots & \cdots \\
\cdots & \cdots & \cdots\end{array}$ & $\begin{array}{l}863.237 \\
715.974\end{array}$ \\
\hline & Diferencia o incremento a favor $d$ & $\operatorname{del} 2 .^{\circ} \ldots$ & 147.263 \\
\hline
\end{tabular}


APENDICE 3 (Continuación)

Gruesa de diezmos de Durango

\begin{tabular}{|c|c|c|c|}
\hline \multicolumn{2}{|c|}{ Decenio $1 .^{\circ}$ de 1770 a 1779} & \multicolumn{2}{|c|}{ Decenio $2 .^{\circ}$ de 1780 a 1789} \\
\hline Años & Pesos & Años & Pesos \\
\hline 1770 & 90.954 & 1780 & 102.225 \\
\hline 1771 & 96.193 & 1781 & 117.572 \\
\hline 1772 & 86.574 & 1782 & 104.783 \\
\hline 1773 & 96.174 & 1783 & 119.812 \\
\hline 1774 & 100.360 & 1784 & 104.791 \\
\hline 1775 & 86.949 & 1785 & 107.416 \\
\hline 1776 & 94.894 & 1786 & 113.655 \\
\hline 1777 & 89.661 & 1787 & 106.023 \\
\hline 1778 & 98.878 & 1788 & 103.707 \\
\hline \multirow[t]{5}{*}{1779} & 102.391 & 1789 & 100.329 \\
\hline & 943.028 & & 1.080 .313 \\
\hline & Segundo decenio & $\ldots$ & 1.080 .313 \\
\hline & Primer decenio ... & $\begin{array}{llll} & \ldots & \cdots & \cdots\end{array}$ & 943.028 \\
\hline & Diferencia a favor $d$ & $\ldots \ldots \ldots$ & 137.285 \\
\hline
\end{tabular}

Fuente: «Ensayo Apologético...» (1975), vol. I, pp. 368-371. 


\section{APENDICE 4}

ALCABALAS

Valor entero en los veintiséis años desde el de 1765 al de 1790

\begin{tabular}{|c|c|c|c|}
\hline Años & Valores & Años & Valores \\
\hline \multirow[t]{2}{*}{$\begin{array}{l}1765 \\
1766 \\
1767 \\
1768 \\
1769 \\
1770 \\
1771 \\
1772 \\
1773 \\
1774 \\
1775 \\
1776 \\
1777\end{array}$} & $\begin{array}{l}1.226 .187 .4 .1 / 2 \\
1.389 .124 .7 . \\
1.365 .992 .1 .1 / 2 \\
1.358 .319 .5 . \\
1.525 .105 .3 . \\
1.634 .273 .1 . \\
1.340 .290 .3 . \\
1.282 .462 .6 .1 / 2 \\
2.093 .381 .3 .1 / 2 \\
1.688 .245 .5 .1 / 2 \\
1.488 .690 .3 . \\
1.367 .466 . \\
2.084 .514 .4 .\end{array}$ & $\begin{array}{l}1778 \\
1779 \\
1780 \\
1781 \\
1782 \\
1783 \\
1784 \\
1785 \\
1786 \\
1787 \\
1788 \\
1789 \\
1790\end{array}$ & $\begin{array}{l}2.773 .967 .4 .1 / 2 \\
2.254 .162 . \\
2.360 .703 . \\
3.466 .503 \cdot 6.1 / 2 \\
3.333 .651 \cdot 7 . \\
3.229 .178 .2 . \\
3.898 .936 .6 .1 / 2 \\
4.038 .828 .5 . \\
3.450 .336 .6 .1 / 2 \\
3.708 .630 . \\
3.279 .501 .6 .1 / 2 \\
3.256 .281 .2 .1 / 2 \\
3.577 .658 .5 .\end{array}$ \\
\hline & 19.844.053. $7.1 / 2$ & & 42.628.340. 4 \\
\hline \multicolumn{3}{|c|}{$\begin{array}{l}\text { Rebajante } 8.809 .877 \text { ps. del } 2 \% \text { de indulto de revista en } \\
\text { los últimos } 10 \text { años } \ldots \ldots \ldots \ldots \ldots \\
\ldots\end{array}$} & 8.809 .877 \\
\hline \multicolumn{3}{|c|}{$\begin{array}{l}\text { Nota: Que a estos } 33.818 .463 \text { ps. } 4 \text { rs. que importan los } \\
\text { últimos } 13 \text { años rebajado del } 2 \% \text { de indulto deben añadirse } \\
\text { lo menos } 400.000 \text { que importaría la } 4 .^{.} \text {parte de Alcabala de } \\
\text { fincas, ganados, muebles, etc., que siempre ha pagado el } 6 \% \\
\text { íntegro } \ldots \ldots \ldots \\
\ldots\end{array}$} & 33.818.463. 4 \\
\hline \multicolumn{3}{|c|}{$\begin{array}{llllllllll}\operatorname{TotaL} & \ldots & \ldots & \ldots & \ldots & \ldots & \ldots & \ldots & \ldots & \ldots\end{array}$} & $\begin{array}{l}34.218 .463 .4 . \\
19.844 .053 .7 .1 / 2\end{array}$ \\
\hline \multicolumn{3}{|c|}{ 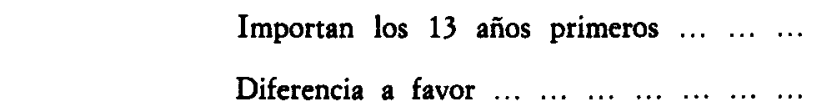 } & $14.374 .409 .4 .1 / 2$ \\
\hline
\end{tabular}


APENDICE 4 (Continuación)

Productos de la Aduana de México en los veintiséis años desde el de 1766 basta el de 1791, en que no se incluyen fincas, censos, muebles y otros frutos

\begin{tabular}{|c|c|c|c|}
\hline Años & Valores & $A \tilde{n} o s$ & Valores \\
\hline 1766 & 626.566. 5. 7. & 1779 & 597.225 .0 .11$. \\
\hline 1767 & 425.305. 5. 7. & 1780 & 616.737. 7. 2. \\
\hline 1768 & 355.714 .7 .11$. & 1781 & 894.400. 6. 7. \\
\hline 1769 & 536.393. 3. 4. & 1782 & 599.853. 5. 2. \\
\hline 1770 & 585.166. 1. 2. & 1783 & 556.764. 7. 5. \\
\hline 1771 & 288.289 & 1784 & 880.648 .6 .6$. \\
\hline 1772 & 326.025. 4. 1. & 1785 & 870.317 .6 .11$. \\
\hline 1773 & 923.833 .3$. & 1786 & 602.173. 2 \\
\hline 1774 & 472.699. 5. 5. & 1787 & 695.299. 5. 6. \\
\hline 1775 & 410.091 .1 .9$. & 1788 & 1.018 .014 .0 .6 \\
\hline 1776 & 345.939 .0 .9$. & 1789 & 674.214. 5. 6. \\
\hline 1777 & 760.345 .5 .6$. & 1790 & 647.493. 5 \\
\hline \multirow[t]{4}{*}{1778} & 705.292.6. 1. & 1791 & 748.869. 7. 1. \\
\hline & 6.661 .963 .2 .2 & & 9.462.014. 2. 3. \\
\hline & $\begin{array}{l}\text { Segundo trecenio .. } \\
\text { Primer trecenio ... }\end{array}$ & $\begin{array}{lll}\ldots & \ldots & \ldots \\
\ldots & \ldots & \ldots\end{array}$ & $\begin{array}{ll}9.462 .014 .2 . & 3 . \\
6.661 .963 .2 . & 2 .\end{array}$ \\
\hline & Diferencia a favor & $\begin{array}{lll}. . & \ldots & \ldots\end{array}$ & 2.800 .051 .0 .1 \\
\hline
\end{tabular}

FUENTE: «Ensayo Apologético...» (1975), vol. I, pp. 374-375. 


\section{APENDICE 5}

\section{TRIBUTOS}

Valor entero de este Ramo en los veintiséis años de 1765 a 1790

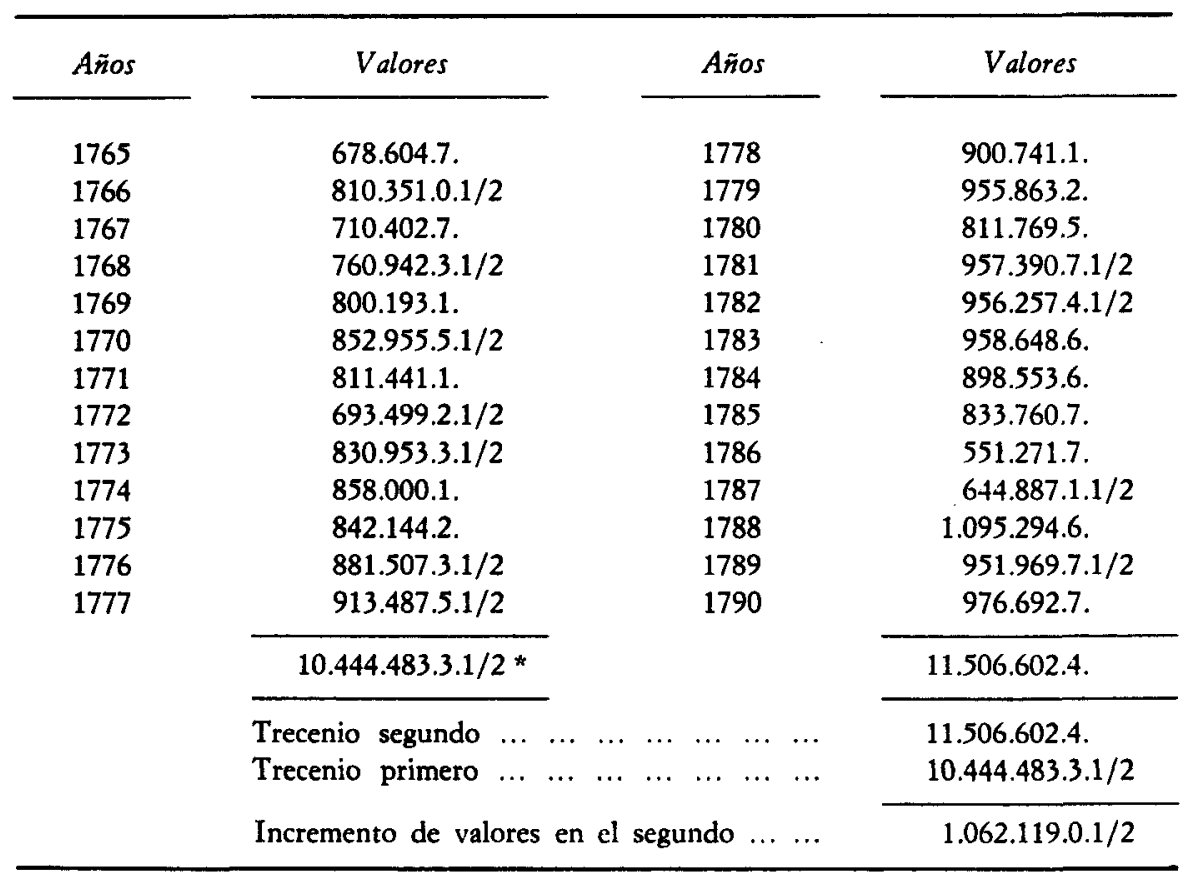

* «Regulando el Tributo a peso por cabeza de los Indios y castas que le contribuyen, será el aumento de la Población 1.062.119 personas por ser esta propia cantidad la que ha aumentado el Tributo en los 13 años últimos.»

FunNTE: «Ensayo Apologético...» (1975), vol. I, p. 367. 
APENDICE 6 (A)

Distribución de la población de Nueva España (1793-1810)

\begin{tabular}{|c|c|c|c|c|c|c|}
\hline \multirow{2}{*}{$\begin{array}{l}\text { Intendencias } \\
\text { y gobiernos }\end{array}$} & \multicolumn{2}{|c|}{1793} & \multicolumn{2}{|c|}{1803} & \multicolumn{2}{|c|}{1810} \\
\hline & Total & $\%$ & Total & $\%$ & Total & $\%$ \\
\hline México $\ldots \ldots \ldots$ & 1.162 .856 & 24,0 & 1.511 .900 & 25,9 & 1.591 .844 & 26,0 \\
\hline $\begin{array}{lllll}\text { Puebla } & \ldots & \ldots & \ldots & \ldots\end{array}$ & 566.443 & 11.7 & 813.300 & 13,9 & 811.285 & 13,2 \\
\hline Oaxaca $\ldots \ldots \ldots$ & 411.366 & 8,5 & 534.800 & 9,1 & 596.326 & 9,7 \\
\hline Guanajuato ... ...... & 397.924 & 8,2 & 517.300 & 8,8 & 576.600 & 9,4 \\
\hline S. L. Potosí ... ... & 242.280 & 5,0 & 230.000 & 3,9 & 173.651 & 2,8 \\
\hline $\begin{array}{llll}\text { Zacatecas } & \ldots & \ldots & \ldots\end{array}$ & 118.027 & 2,4 & 153.300 & 2,6 & 140.723 & 2,2 \\
\hline Durango $\ldots \ldots \ldots$ & 122.866 & 2,5 & 159.700 & 2,7 & 177.400 & 2,8 \\
\hline Sonora $\ldots \ldots \ldots$ & 93.396 & 1,9 & 121.400 & 2,0 & 135.385 & 2,2 \\
\hline Yucatán.$\ldots \ldots \ldots$ & 358.261 & 7,4 & 465.800 & 7,9 & 528.700 & 8,6 \\
\hline Guadalajara . . . ... & 485.000 & 10,0 & 630.500 & 10,8 & 517.674 & 8,4 \\
\hline Veracruz $\ldots \ldots \ldots$ & 120.000 & 2,4 & 156.000 & 2,6 & 185.935 & 3,0 \\
\hline $\begin{array}{llll}\text { Valladolid } & \ldots & \ldots & \ldots\end{array}$ & 289.314 & 5,9 & 376.400 & 6,4 & 394.689 & 6,4 \\
\hline N. México $\ldots \ldots . .$. & 30.953 & 0,6 & 40.200 & 0,6 & 34.205 & 0,5 \\
\hline V. California $\ldots \ldots$ & 12.666 & 0,2 & 9.000 & 0,1 & 4.496 & 0,07 \\
\hline N. California $\ldots \ldots$ & & & 15.600 & 0,2 & 20.871 & 0,3 \\
\hline Coahuila & 13.000 & 0,2 & 16.900 & 0,2 & 42.937 & 0,7 \\
\hline N. R. León ... ... & & & 26.000 & 0,4 & 43.739 & 0,7 \\
\hline N. Santander $\ldots \ldots$ & & & 38.000 & 0,6 & 56.715 & 0,9 \\
\hline $\begin{array}{lllll}\text { Texas } & \ldots & \ldots & \ldots & \ldots\end{array}$ & & & 21.000 & 0,3 & 3.334 & 0,05 \\
\hline Tlaxcala $\ldots \ldots \ldots$ & 59.117 & 1,2 & & & 85.845 & 1,4 \\
\hline Total . ..... & 4.483 .469 & & 5.837 .100 & & 6.122 .354 & \\
\hline
\end{tabular}


APENDICE 6 (B)

Evolución de la densidad demográfica por regiones

\begin{tabular}{|c|c|c|c|c|}
\hline Intendencias y gobiernos & $K m^{2}$ & 1793 & 1803 & 1810 \\
\hline $\begin{array}{llllllll}\text { México } & \ldots & \ldots & \ldots & \ldots & \ldots & \ldots & \ldots\end{array}$ & 116.843 & 9,9 & 12,9 & 13,6 \\
\hline $\begin{array}{lllllllll}\text { Puebla } & \ldots & \ldots & \ldots & \ldots & \ldots & \ldots & \ldots\end{array}$ & 53.148 & 10,6 & 15,3 & 15,2 \\
\hline $\begin{array}{llllllllll}\text { Oaxaca } & \ldots & \ldots & \ldots & \ldots & \ldots & \ldots & \ldots & \ldots\end{array}$ & 87.666 & 4,6 & 6,1 & 6,8 \\
\hline $\begin{array}{llllllll}\text { Guanajuato } & \ldots & \ldots & \ldots & \ldots & \ldots & \ldots & \ldots\end{array}$ & 17.959 & 22,1 & 28,8 & 32,1 \\
\hline $\begin{array}{llllllll}\text { S. L. Potosí } & \ldots & \ldots & \ldots & \ldots & \ldots & \ldots\end{array}$ & 46.456 & 5,2 & 4,9 & 3,7 \\
\hline $\begin{array}{lllllllll}\text { Zacatecas } & \ldots & \ldots & \ldots & \ldots & \ldots & \ldots & \ldots\end{array}$ & 46.426 & 2,5 & 3,3 & 3,0 \\
\hline $\begin{array}{llllllll}\text { Durango } & \ldots & \ldots & \ldots & \ldots & \ldots & \ldots & \ldots\end{array}$ & 332.628 & 0,3 & 2,0 & 0,5 \\
\hline $\begin{array}{lllllllll}\text { Sonora } & \ldots & \ldots & \ldots & \ldots & \ldots & \ldots & \ldots & \ldots\end{array}$ & 377.377 & 0,2 & 0,3 & 0,3 \\
\hline $\begin{array}{llllllll}\text { Yucatán } & \ldots & \ldots & \ldots & \ldots & \ldots & \ldots & \ldots\end{array}$ & 117.828 & 3,0 & 3,9 & 4,4 \\
\hline $\begin{array}{lllllll}\text { Guadalajara } & \ldots & \ldots & \ldots & \ldots & \ldots & \ldots\end{array}$ & 189.487 & 2,5 & 3,3 & 2,7 \\
\hline $\begin{array}{llllllll}\text { Veractuz } & \ldots & \ldots & \ldots & \ldots & \ldots & \ldots & \ldots\end{array}$ & 81.634 & 1,4 & 1,9 & 2,2 \\
\hline $\begin{array}{llllllll}\text { Valladolid } & \ldots & \ldots & \ldots & \ldots & \ldots & \ldots & \ldots\end{array}$ & 67.933 & 4,2 & 5,5 & 5,8 \\
\hline $\begin{array}{llllllll} & \text { N. México } & \ldots & \ldots & \ldots & \ldots & \ldots & \ldots\end{array}$ & 112.545 & 0,2 & 0,3 & 0,3 \\
\hline $\begin{array}{llllll}\text { Baja California } & \ldots & \ldots & \ldots & \ldots & . .\end{array}$ & 143.811 & 0,08 & 0,06 & 0,03 \\
\hline $\begin{array}{llllll}\text { Alta California } & \ldots & \ldots & \ldots & \ldots & \ldots\end{array}$ & 41.891 & & 0,3 & 0,4 \\
\hline $\begin{array}{llllllll}\text { Coahuila } & \ldots & \ldots & \ldots & \ldots & \ldots & \ldots & \ldots\end{array}$ & 132.121 & 0,09 & 0,1 & 0,3 \\
\hline $\begin{array}{llllllll} & \text { N. R. León } & \ldots & \ldots & \ldots & \ldots & \ldots & \ldots\end{array}$ & 51.669 & & 0,5 & 0,8 \\
\hline $\begin{array}{lllllll} & \text { N. Santander } & \ldots & \ldots & \ldots & \ldots & \ldots\end{array}$ & 102.373 & & 0,3 & 0,5 \\
\hline $\begin{array}{lllllllll}\text { Texas } & \ldots & \ldots & \ldots & \ldots & \ldots & \ldots & \ldots & \ldots\end{array}$ & 215.824 & & 0,09 & 0,01 \\
\hline
\end{tabular}

El área en kilómetros cuadrados es una estimación de A. Humboldt basada en los límites administrativos de las intendencias y gobiernos de 1803. 


\section{APENDICE $6(\mathrm{C})$}

Tendencias demográficas urbanas de Nueva España-México (1742-1818)

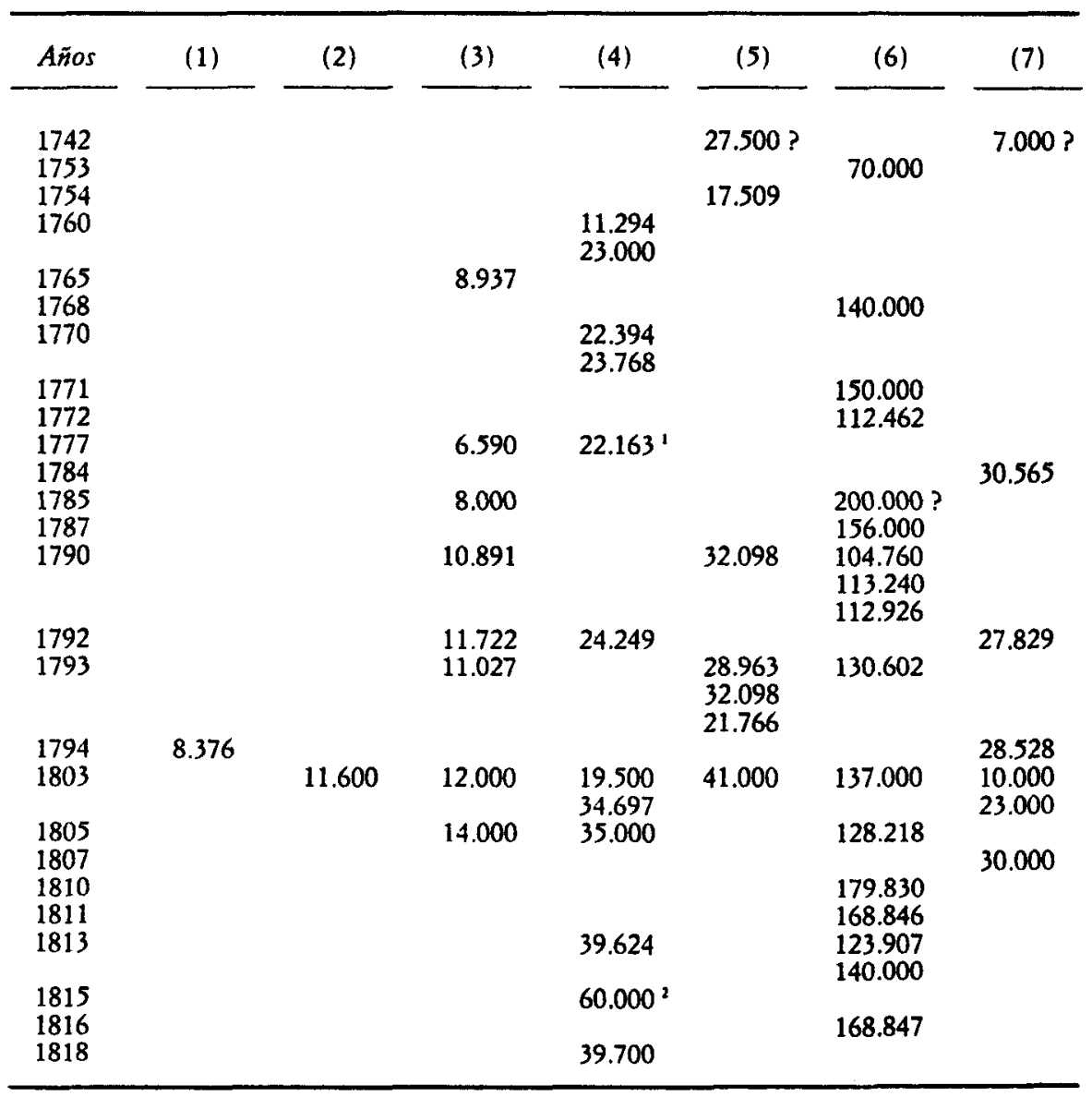

\footnotetext{
(1) Aguascalientes.

(2) Chihuahua.

(3) Durango.

(4) Guadalajara.

Incluye pueblos vecinos.

2 Estimación Cabildo.

(5) Guanajuato.

(6) México.

(7) Mérida.
} 
APENDICE 6 (C) (Continuación)

Tendencias demográficas urbanas de Nueva España-México (1742-1818)

\begin{tabular}{|c|c|c|c|c|c|c|}
\hline Años & $(8)$ & (9) & $(10)$ & (11) & (12) & (13) \\
\hline 1746 & & & 50.366 & & 26.721 & \\
\hline 1752 & & 8.905 & & & & \\
\hline 1760 & & 12.000 & & & & \\
\hline 1773 & & & & & 27.399 & \\
\hline 1776 & & 19.000 & & & & 19.000 \\
\hline 1777 & & & 56.220 & & 25.581 & 19.653 \\
\hline 1778 & & & & & $47.000^{3}$ & \\
\hline 1790 & & & 52.717 & 16.000 & & \\
\hline 1792 & & & & & & $\begin{array}{l}18.241 \\
24.000 \\
22.113\end{array}$ \\
\hline 1793 & & 17.093 & 56.856 & & & \\
\hline 1797 & & & 57.168 & & $45.359^{3}$ & 19.062 \\
\hline 1800 & & & & & 40.000 & \\
\hline 1803 & & 18.000 & 67.800 & 16.000 & $\begin{array}{l}50.000 \\
35.000 \\
27.000\end{array}$ & \\
\hline 1804 & & & & 19.000 & 31.641 & 18.626 \\
\hline 1805 & & 21.000 & & 15.000 & & \\
\hline 1808 & & & & & & 17.599 \\
\hline 1810 & & & & & 58.000 & 17.056 \\
\hline 1815 & & & & & & 15.702 \\
\hline
\end{tabular}

(8) Monterrey.

(9) Valladolid-Morelia.

(10) Puebla.

(11) Veracruz.

(12) Querétaro.

3 Incluye binterland.

(13) Antequera-Oaxaca.

Fuenre: P. Pérez Herrero (1987). 


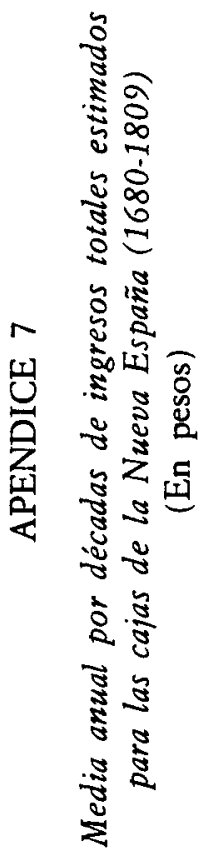

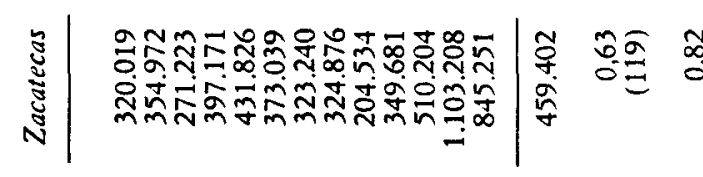

苞|

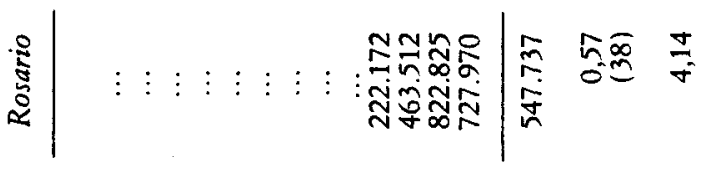

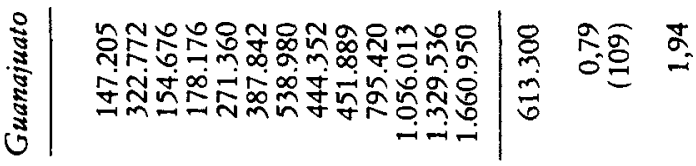

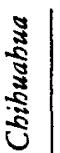

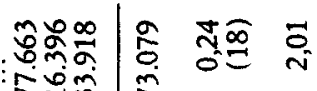

实商|

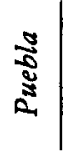

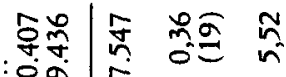

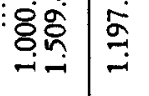

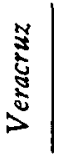

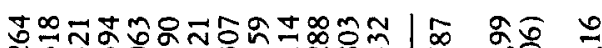

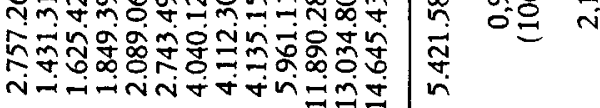

i-i-iñưं

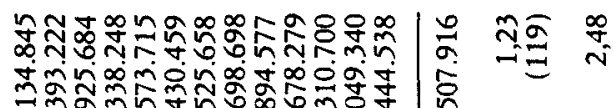

这

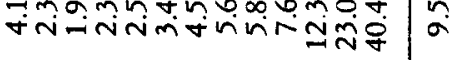

รัँ

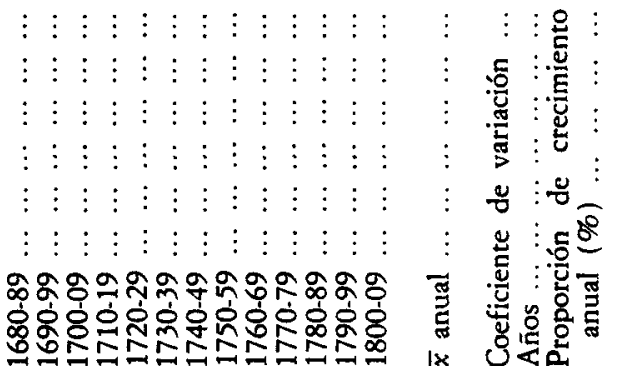




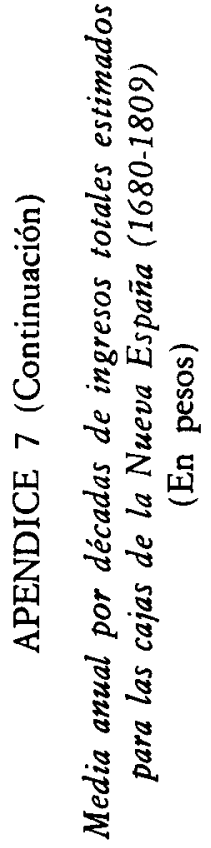

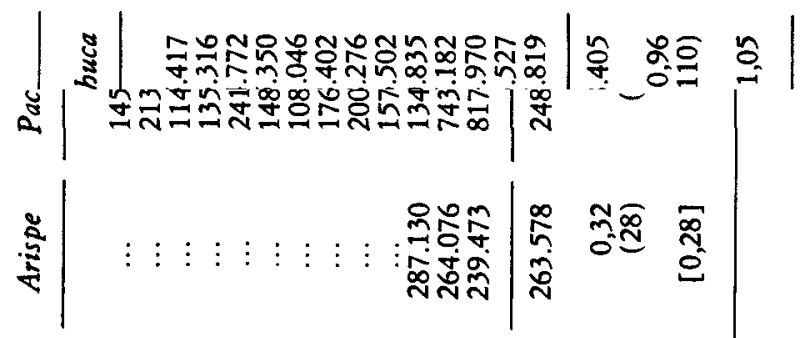

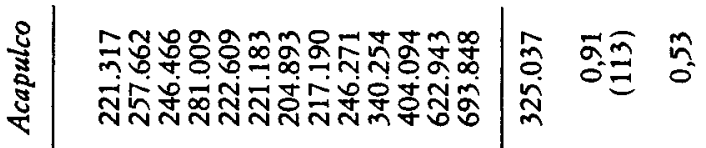

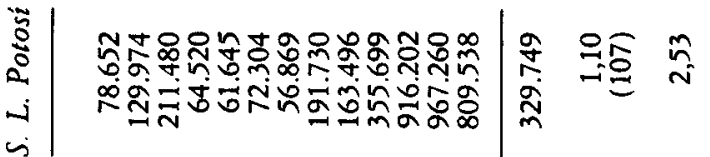

is

紊

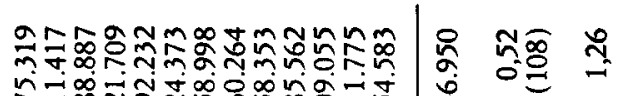

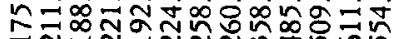

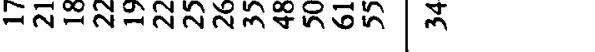

$\frac{0}{\frac{3}{3}} \mid$

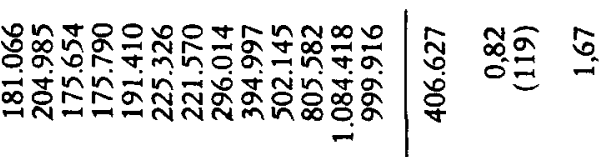

ชู

mo

:

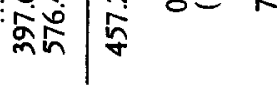

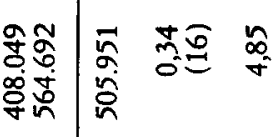

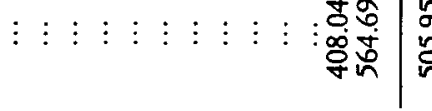

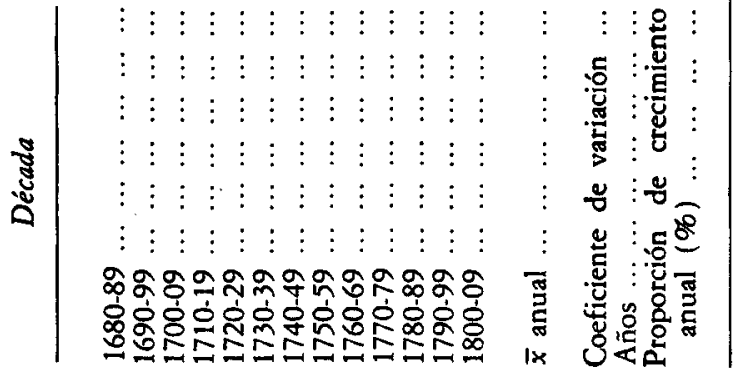




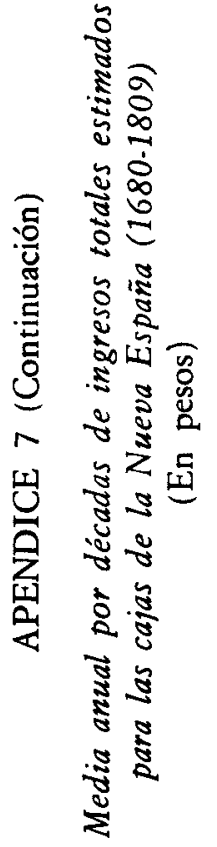

$\left.\right|_{0} \mid \begin{gathered}* \\ \overline{8} \\ 0\end{gathered}$






\section{BIBLIOGRAFIA}

AKCAVO"MTSTUURTC $\delta^{-}$DE HACIENDA (Méxicö), 635-5, 635-8, 550-54.

Alamán, Lucas (1849-1852): Historia de México desde los primeros movimientos que prepararon su independencia en el año de 1808 basta la época presente, 5 vols., México.

Arrís Espriú, Gloria (1986): Regatones y maquileros. El mercado del trigo en la ciudad de México (siglo XVIII), México, CIESAS.

Assadourian, Carlos Sempat (1982): El sistema de la economia colonial. Mercado interno, regiones y espacio económico, Lima, IEP.

Bakewell, Peter J. (1976): Mineria y sociedad en el México colonial. Zacatecas (15461700). México, FCE.

Barbosa Ramírez, A. René (1977): La estructura económica de la Nueva España, 1519. 1810, México, Ed. Siglo XXI.

BoraH, Woodrow (1951): New Spain's Century of depression, Berkeley, University of California Press.

Brading, David D. (1975): Mineros y comerciantes en el México borbónico (1763-1810), México, FCE.

Cárdenas, Enrique (1984): «Algunas cuestiones sobre la depresión mexicana del siglo XIX», HISLA. Revista Latinoumericana de Historia Económica y Social, III, pp. 3-22.

Contsworth, John H. (1978): «Obstacles to economic growth in Nineteenth-Century Mexico", American Historial Review, LXXXIII, pp. 80.100; traducido en E. FloresCano (coord.), Ensayos sobre el desarrollo económico de México y América Latina (1500-1975), México, FCE, 1979, pp. 171-186.

- (1986): "The mexican mining industry in the eighteenth Century", en N. JACOBSEN y H. J. Pühle (eds.), The economies of Mexico and Peru during the late colonial period, 1760-1810, Berlín, Colloguium Verlag, pp. 26-45.

- (1988): «La historiografía económica de México», Revista de Historia Económica, VI, 2, pp. 277-291.

Chaunu, Pierre y Huguette (1955-1960): Seville et l'Atlantique, 12 vols., París.

Chevalier, François (1953): La formation des grands domaines au Mexique. Terre et société aux XVI'-XVII', París, Institute d'Ethnologie; existe traducción al español: Mé. xico, FCE, 1976.

Chiaramonte, Juan Carlos (1981): «En torno a la recuperación demográfica y la depresión económica novohispana durante el siglo XvIr», Historia Mexicana, XXX, 4, pp. 561-604.

Equipo Madrid (1988): Carlos III, Madrid y la Ilustración, Madrid, Siglo XXI.

«Ensayo Apologético por el comercio libre, con reflexiones imparciales sobre las pretensiones de negociantes de esta Nueva España, refutadas por el señor fiscal de Real Hacienda y sostenidas en un papel póstumo» (1975), en E. Florescano y F. Castillo, Controversia sobre la liberiad de comercio en Nueva España, 1776-1818, México, IMCE, pp. 368-370.

Fonseca, Fabián de, y Urrutia, Carlos (1845-1853): Historia General de Real Hacienda, 6 vols., México, Imp. V. G. Torres.

Garavaglia, Juan Carlos, y Grosso, Juan Carlos (1985): Estado borbónico y presión fiscal en la Nueva España, 1750-1821, México, Reporte de Investigación, UAMIztapalapa.

García Martínez, Bernardo (1970): La Casa de Moneda, siglos XVI-XIX, México, Secretaría de Hacienda y Crédito Público.

GAKNER, Richard L. (1980): «Silver production and entreprenurial structure in 18th-Century Mexico", Jabrbucb fur Geschichte von Staat, Wirtschaft und Gesellschaft Lateinamerikas, XVII, pp. 157-185.

- (1982): "Exportaciones de circulante en el siglo xvin (1750-1810)», Historia Mexicana, XXX, 4, pp. 544.598 .

- (1985): "Price trends in eighteenth-Century Mexico", Hispanic American Historical Review, 65, 2, pp. 279-325. 
Gibson, Charles (1967): Los aztecas bajo el dominio español, 1519-1810, México, Siglo XXI (1." ed. en inglés, 1964).

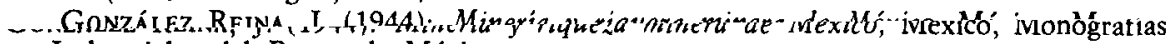
Industrjales del Banco de México.

Howe, W. (1949): The mining guild of New Spain and its Tribunal General, 1770-1821, Cambridge (Mass.), Harvard University Press.

Humboldt, Alejandro de (1978): Ensayo político sobre el reino de la Nueva España, México, Porrúa.

IsraEl, Jonathan I. (1979): "México y la crisis general del siglo xvil», en E. FloresCano (coord.), Ensayos sobre el desarrollo de México y América Latina (1500-1975), México, FCE, pp. 128-153.

KLEIN, Herbert S. (1985): «La economía de la Nueva España, 1680-1809: un análisis a partir de las Cajas Reales», Historia Mexicana, XXXIV, 4, pp. 561-609.

- (1986): "The economies of New Spain and Peru, 1680-1809: the view from the royal tresasuries", trabajo presentado al VII Simposio Internacional de Historia Económica, Lima.

LEIBY, John (1986): Colonial bureaucrats and the mexican economy. Growth of a Patrimonial State, 1763-1821, Nueva York, Peter Lang.

Lerdo de Tejada, Miguel (1967): Comercio exterior de México, México, Banco Nacional de Comercio Exterior.

LERNER, Victoria (1968): «Consideraciones sobre la población de la Nueva España (1793. 1810). Según Humboldt y Navarro y Noriega», Historia Mexicana, XVII, 3, pp. 327. 348.

Lindo Fuentes, Héctor (1977): «La utilidad de los diezmos como fuente para la historia económica", Historia Mexicana, XXVI, 2, pp. 273-289.

Lira, Andrés, y Muro, Luis (1977): "El siglo de la integración», en D. Cosio Villegas (coord.), Historia General de México, México, El Colegio de México, pp. 83-181.

López Rosado, Diego G. (1965): Ensayos sobre la bistoria económica de México, México, UNAM.

Lynch, John (1970): España bajo los Austrias, Barcelona, Ed. Península.

Mayo, John (1987): "Consuls and silver contraband on Mexico's West coast in the era of Santa Anna", Journal of Latin American Studies, XIX, 2, pp. 389-411.

Medina Rubio, Arístides (1983): La Iglesia y la producción agrícola en Puebla, 15401795, México, El Colegio de México.

MENÉNDEZ VAldÉs, José (1980): Descripción y censo general de la intendencia de Guadalajara, 1789-1793 (estudio preliminar de R. M. Serrera), Guadalajara.

Miranda, José (1962): «La población indigena de México en el siglo xvil», Historia Me. xicana, XII, 2, pp. 182-189.

Morin, Claude (1979): Michoacán en la Nueva España del siglo XVIII. Crecimiento y desigualdad en una economia colonial, México, FCE.

Muro, Luis (1971): «Revillagigedo y el comercio libre (1791-1792)», en Extremos de México. Homenaje a don Daniel Cosio Villegas, México, El Colegio de México, pp. 299. 344.

Orozco y Berra, Manuel (1853-1855): «Moneda en México», en Diccionario Universal de Historia y Geografia, 7 vols., México, 1853-1855, vol. V.

- (1857): «Informe sobre la acuñación en las Casas de Moneda de la República», en G. Manuel Siliceo (ed.), Memoria de la Sccretaría de Fomento, Colonización, Industria y Comercio de la República Mexicana, México.

Ortiz de la TABla, Javier (1978): Comercio exterior de Veracruz, 1778-1821. Crisis de dependencia, Sevilla, EEHA.

Palerm, Angel (1979): «Sobre la formación del sistema colonial. Apuntes para una discusiónm, en E. Florescano (coord.), Ensayos sobre el desarrollo económico de México y América Latina (1500-1975), México, FCE.

Pastor, Rodolfo (1977): «La alcabala como fuente para la historia económica y social de la Nueva España», Historia Mexicana, XXVII, 1, pp. 1-16. 
Pérez Herrero, Pedro (1984): «Comercio y precios en la Nueva España. Presupuestos teóricos y materiales para una discusión», Revista de Indias, XLIV, 174, pp. 465-488.

- (1987): "Las transformaciones del espacio colonial en estructura nacional. México, 1765-1854: planteamientos y problemas», ponencia presentada en la Segunda Trobada Americanista a Mataró: «L'Amèrica Espanyola: 1750-1850. De l'Imperi a les Repúbliques» (13 de julio).

- (1988): Plata y libranzas. La articulación comercial del México borbónico, México, El Colegio de México.

Potash, Robert A. (1953): «El "Comercio exterior de México" de Miguel Lerdo de Tejada: un error estadísticom, El Trimestre Económico, XX, 79, pp. 474-479.

Pradeau, A. F. (1950): Historia numismática de México desde la época precortesiana hasta 1823, México, Banco de México.

- (1957): «Esquema del número aproximado de monedas mexicanas», Numisma, vol. VII.

Rabell Romero, Cecilia (1984): La población novobispana a la luz de los registros parroquiales: avances y perspectivas de investigación (tesis de maestría), México, El Colegio de México (mss.).

- (1985): Los diezmos de San Luis de la Paz. Economía de una región del Bajío en el siglo XVIII, México, UNAM.

Recopilación de las leyes de los Reinos de las Indias mandadas imprimir y publicar por la magestad católica del rey don Carlos II (1681), 4 vols., Madrid, Julián de Paredes; existe ed. facsimilar: Madrid, Cultura Hispánica, 1973.

Romano, Ruggiero (1986): «Algunas consideraciones sobre la historia de precios en América Latina", HISLA. Revista Latinoamericana de Historia Económica y Social, VII, pp. 65-103.

SalvuccI, Richard J. (1987): Texilles and capitalism in Mexico. An economic bistory of the obrajes, 1539-1840, Princeton, Princeton University Press.

Salvucci, Richard J., y Linda, K. (1986): «Growth and productivity change in the Mexican economy, 1750-1850: estimates and conjetures», ponencia presentada al VII Simposio de Historia Económica: «El Sistema Colonial en Mesoamérica y los Andes», Lima, junio.

SuÁrez, Clara Elena (1985): La politica cerealera y la economia novohispana: el caso del trigo, México, CIESAS.

TePASKE, John H. (1986): «General tendencies and secular trends in the economies of Mexico and Peru, 1750-1810: the view from the Cajas of Mexico and Limas, en N. JacoBsen y H. J. Pühle (eds.), The economies of Mexico and Peru during the late colonial period, 1760-1810, Berlín, Colloquium Verlag, pp. 316-339.

TePaske, John H., y Hernández Palomo, José y Mari luz (1976): La Real Hacienda de Nueva España: La Real Caja de México (1576-1816), México, INAH.

TePaske, John H., y KLEIN, Herbert R. (1981): «The seventeenth-Century Crisis in New Spain: Myth or reality», Past E Present, 90, pp. 116-135.

- (1986): Ingresos y egresos de la Real Hacienda de Nueva España, México, INAH.

Van YounG, Eric (1987): «The rich get richer and the poor get skewed: real wages and popular living standards in late colonial Mexico", trabajo presentado al ALL-UC Group in Economic History, Huntington, mayo.

- (1988): «A modo de conclusión: el siglo paradójico», en Arij Ouweneel y Cristina Torales Pacheco (comps.), Empresarios, indios y Estado. Perfil de la economia mexicana (siglo XVIII), Amsterdam, CEDLA, pp. 206-231. 